\title{
A hydro-geochemical analysis of the saturation process with salt water of a bentonite crushed granite rock mixture in an engineered nuclear barrier
}

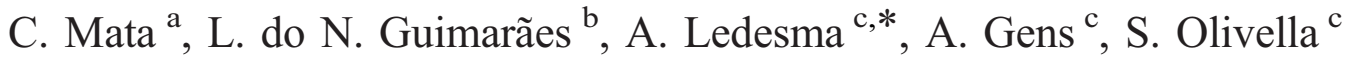 \\ a Ingeniería de Instrumentación y Control, S.A., Madrid, Spain \\ ${ }^{\mathrm{b}}$ Federal University of Pernambuco, Recife, Brazil \\ ${ }^{\mathrm{c}}$ Department of Geotechnical Engng. and Geosciences, Technical University of Catalonia (UPC), Barcelona, Spain
}

Available online 10 August 2005

\begin{abstract}
A MX-80 sodium bentonite crushed granite rock mixture is being saturated in the Äspö Hard Rock Laboratory managed by SKB (the Swedish Company of nuclear waste management) as part of the "Backfill and Plug Test Project". The Äspö Hard Rock Laboratory is placed in the Swedish Island of Äspö, an underground full-scale laboratory where different testing construction procedures and handling techniques are being studied. The groundwater of Äspö has a variable salt concentration according to the zone considered. The added water during the mixing process of both materials had an average salt concentration of $6 \mathrm{~g} / \mathrm{L}$. However, backfill is being saturated with salt water containing higher salt content (up to $16 \mathrm{~g} / \mathrm{L}, 50 / 50$ of $\mathrm{NaCl}$ and $\mathrm{CaCl}_{2}$ by mass) to speed up the saturation process. The mixture swelling capacity is small due to the low backfill bentonite content, but its activity is still large if compared with natural clayey soils. A coupled hydro-chemical approach was used to simulate the backfill hydration process, comparing the results with in situ measurements. An intrinsic permeability law, depending on salt concentration in the liquid phase, was incorporated into the model. The retention curve was also determined taking into account the effect of the chemical species on backfill behaviour. The simulation of the saturation process shows the importance of studying these problems with a HC (hydro-chemical) formulation, especially if long term behaviour of such mixtures is going to be reproduced. (C) 2005 Elsevier B.V. All rights reserved.
\end{abstract}

Keywords: Nuclear waste barrier; Bentonite-granular material mixtures; Hydraulic conductivity; Reactive transport; Hydro-chemical coupling; Clay-fluid system

\section{Introduction}

During the last few years, considerable experimental research has been carried out on compacted bento-

\footnotetext{
* Corresponding author.

E-mail address: alberto.ledesma@upc.edu (A. Ledesma).
}

nite-granular soil mixtures as sealing materials in engineered barriers for nuclear waste disposal sites. In such a problem, the analysis of chemical effects of salts on the hydro-mechanical properties of the barriers becomes important because of the possible hydration of the repositories with seawaters. It is well-known that mechanical and hydraulic behaviour 
of active clayey soils can be strongly affected by chemical conditions of their environment. In the context of isolating hazardous wastes, i.e. nuclear, industrial or mining wastes, these changes can notably affect the safety of the barrier. Much of the research refers to experimental work concerning chemical aspects of the hydro-mechanical properties of saturated and unsaturated clays, limes and sandy soils. Most of the experiments studied the effect of pore water chemistry on saturated hydraulic conductivity (Goldenberg and Magaritz, 1983; Fernandez and Quigley, 1985; Yanful et al., 1995; Petrov and Rowe, 1997; Dixon et al., 1999; Dixon, 2000). Some other works analysed the effect on swelling pressure (Karnland, 1997; Dixon, 2000) or on compressibility (Bolt, 1956; Mesri and Olsen, 1971; Di Maio, 1996). However, only a few considered the influence of chemical components on soil water retention curve (Miller and Nelson, 1992; Mata et al., 2002). The amount of experimental information clearly contrasts with the mathematical models able

en involved in the proble coupled with hydro-mechanj

beless, some models have bee

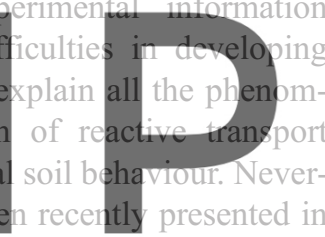

this area (Murad and Cushman, 1998: Guimarães et

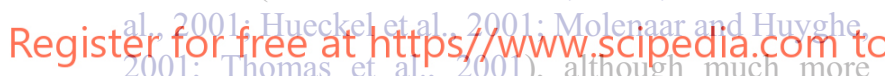

work is still necessary to incorporate the geochemical variables in the current understanding of soil behaviour. In this paper, part of a general fully coupled Thermo-hydro-mechanical-chemical (THMC) formulation from Guimarães et al. (2002) was used to simulate the saturation of a backfill in a large scale field test: the "Backfill and Plug Test Project". This experiment is being performed at Äspö Hard Rock Laboratory (ÄHRL) in Sweden, an underground fullscale laboratory from SKB (Swedish Agency dealing with radioactive waste disposal).

\section{The "Backfill and Plug Test" Project}

The "Backfill and Plug Test" is being carried out at the ZEDEX gallery of the ÄHRL, and is being conducted and developed by Clay Technology (CT) and SKB. The objectives of the project include testing the backfill hydro-mechanical behaviour, studying back- fill interaction with the host rock, and developing techniques and materials for backfilling of tunnels. A detailed project description can be found in SKB (1999). While pure bentonite is being considered as a primary barrier for the canisters containing the radioactive waste, mixtures of bentonite and crushed rock have been considered for the final backfilling of accessing tunnels.

Fig. 1 shows the vertical section of the gallery where the test is being developed. The test region can be divided in four different parts: the inner zone with drainage material only, a zone filled with compacted backfill followed by a third area with crushed granite rock, and finally the concrete plug closing the gallery. The part of the tunnel filled with the mixture is the aim of the current study. Six different backfill sections (A1 to A6) were compacted in six different layers. These sections were mainly instrumented with pore water pressure transducers and psychrometers. The backfill in situ compaction was carried out with a
vibrating plate developed and built for this purpose.
The final slope of the section was $35^{\circ}$ due to compac-
tion technique requirements. Among the scetions,
permeable geotextiles were pladed. The purpose of
these permeable mats is to inject and/or to collect water when performing flow tests.

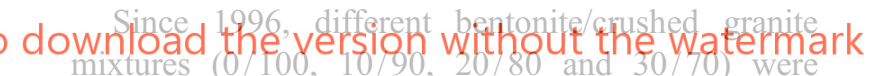

experimentally investigated (Börgesson et al., 1996 and Johannesson et al., 1999) in order to choose the proper material fulfilling the requirements of the Project. The main backfill characteristics had to be low permeability, some swelling capacity and low cost. The ratio $30 / 70$ (30\% of sodium bentonite and $70 \%$ of crushed granite rock with maximum grain size of $20 \mathrm{~mm}$ ) was finally chosen after the testing campaign carried out. The granite rock came from the blasting of the same gallery.

Groundwater in ÄHRL comes from different fractures connected to the Baltic Sea. Depending on the fracture, different salt concentrations can be measured according to the age of the stored water. Mixing water used when preparing the backfill had an average salt concentration of $6 \mathrm{~g} / \mathrm{L}$ and its chemical analysis showed that two main salts were present: sodium chloride and calcium chloride $(50 / 50$ by mass approximately). When the mixing process was finished, backfill was stored and its water content was 


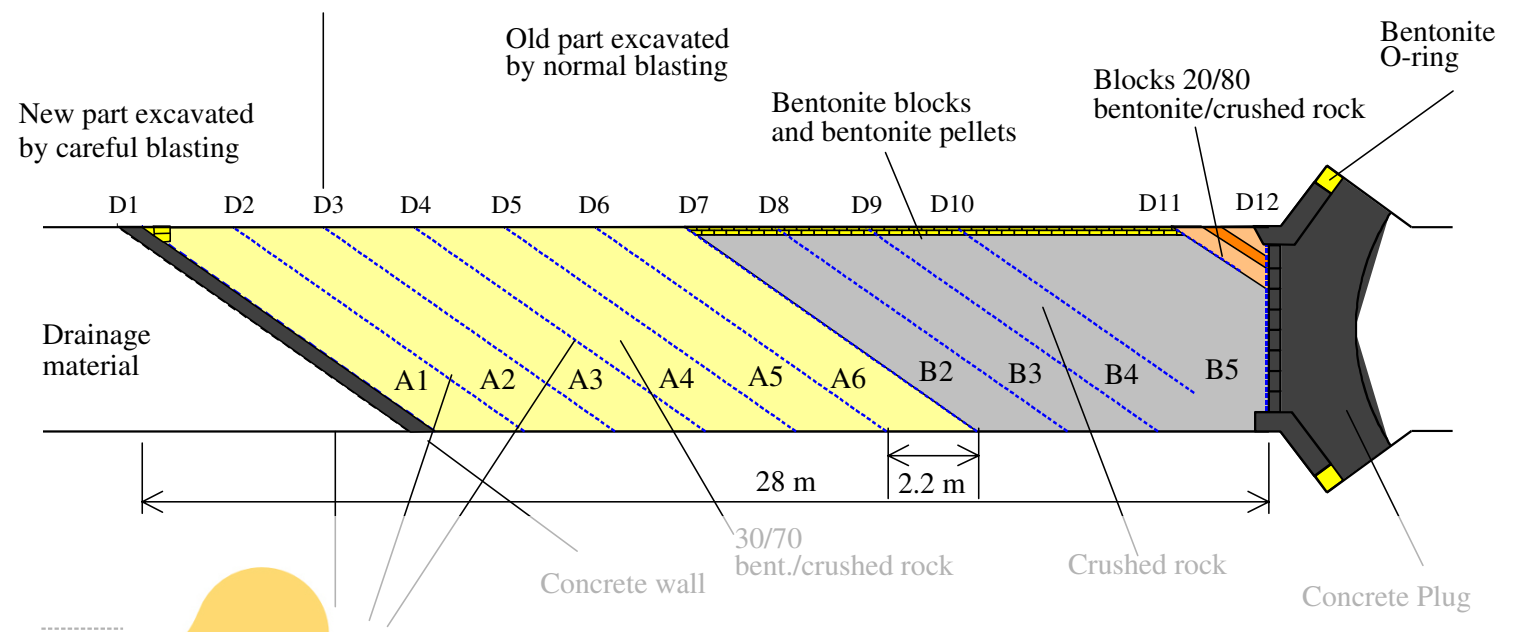

\section{Drainage and deairing \\ layers, permeable mats}

Fig. 1. Vertical section of the ZEDEX gallery. Layers were compacted at $35^{\circ}$ of slope. Among the layers, permeable mats were placed to inject/ collect water from the backfill (Goudarzi et al., 2002).

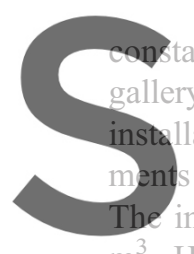

tant until the moment By mid-1998, back started and the proces nitial average dry specific
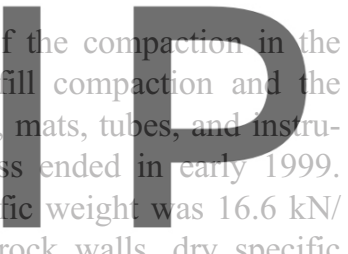

$\mathrm{m}^{3}$. However, close to the rock walls, dry specific Registerefor could be much lower because of compaction tion process started in June 1999, by applying water pressure at the permeable mats. Due to the low backfill permeability, salt concentration in injected water during the saturation process was increased up to 16 $\mathrm{g} / \mathrm{L}$ to speed up its hydration. Additionally, the injection water pressure was less than $100 \mathrm{kPa}$ to avoid backfill hydraulic fracture. The amount of water flowing to the backfill from the host rock was assumed to be very small if compared with the injected one. In fact a water conductive zone in the inner part of the gallery was drained and did not have any significant influence on the saturation process of the backfill.

\section{Basic formulation and geochemical model assumed}

The formulation used in this paper is a fully coupled combination of a pre-existing code (CODE_BRIGHT) that solves non-isothermal multi-phase flow of brine

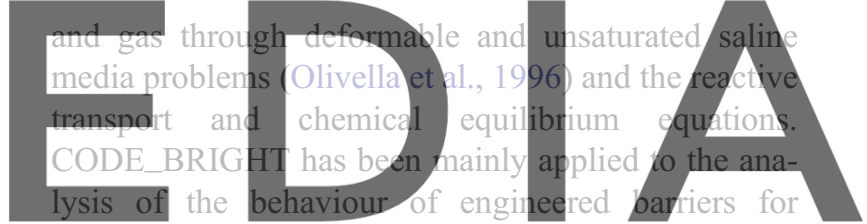

nuclear waste disposal in THM problems (Gens et download the version without the extension of ark the formulation including chemical interactions (Gurrepository problems, although the code can be also used for other THMC applications, as environmental engineering or petroleum engineering (Guimarães, 2002). The formulation considers that geochemical variables, as osmotic suction and concentration of chemical species in the liquid phase and solid phase, may have influence on the hydro-mechanical behaviour of clayey soils.

For this work, only the hydro-chemical (HC) problem was solved to simulate the hydration process in the in situ test. Temperature was assumed constant because this is the case in the experiment. In addition to that, mechanical interactions were not considered in this work, as they play a secondary role if compared with the HC couplings. This is due to the fact that only $30 \%$ of the material is bentonite and it is confined in a gallery. Also, the oedometer tests described below suggest that the $\mathrm{HC}$ interactions are more important than the MC ones for this material. 
Obviously, the consideration of a fully HMC model is a future natural extension of this work.

In the $\mathrm{HC}$ formulation, gas phase movement equation was not taken into account, which is a usual hypothesis in many unsaturated flow analyses. The considered processes were advective flow of water and solutes (Darcy's law), molecular diffusion of solutes (Fick's law), mechanical dispersion of solutes (Fick's law) and ion exchange of $\mathrm{Na}^{+}$and $\mathrm{Ca}^{2+}$.

In addition to those processes, a flow of water driven by an osmotic gradient due to different salt concentrations existing in the pore fluid and in the injected salt water could be considered as well. That mechanism implies that water would tend to move from the backfill to the mats, in order to equilibrate salt concentrations. Note that in this case the direction of this flow is opposite to the flow induced by water pressure gradients.

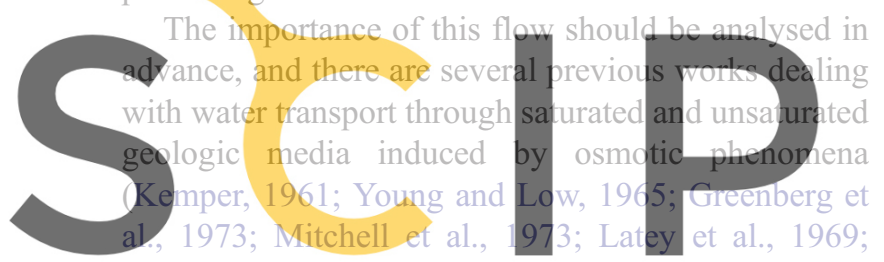

Marine and Fritz, 1981; Barbour and Fredlund, 1989;

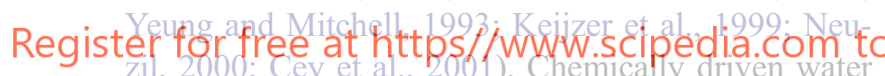

flow (or osmotic flow) in a soil primarily depends on its "osmotic efficiency", $\omega$, parameter, which is a measurement of its ability to act as a semipermeable membrane in preventing the passage of ions while allowing the passage of water. When $\omega=1$ the soil behaves as a perfect semipermeable membrane allowing water and neutral species passing through its porous matrix and preventing the ionic species to pass. This parameter depends on pore fluid chemistry, type of clay and clay porosity. Barbour and Fredlund found values of $\omega$ close to 1 in very dense clays or in dilute electrolyte systems. Appelo and Postma (1993) and Cey et al. (2001) suggest that the semipermeable membrane effect is related to the double layer thickness, and therefore when chemical concentrations increase the value of $\omega$ is thus reduced. As a consequence of those previous works, it is believed that in this experiment, the effect of osmotic flow of water in the MX-80-crushed granite rock mixture can be negligible because of the range of salt concentrations involved in this problem and the high backfill porosity $(>0.35)$.

\subsection{Basis of the formulation of reactive transport in an unsaturated porous medium}

Full details of the coupled formulation of the reactive transport equations and the THM problem can be found in Guimarães (2002), and only a brief summary is provided here, considering specifically the $\mathrm{HC}$ interactions. The reactive transport formulation has two main components: transport equations and the chemical equilibrium model. The transport equations describe the mass continuity of each chemical species in the porous medium. In the chemical equilibrium problem, a relationship between the species concentrations is established that allows a reduction in the degrees of freedom of the reactive transport problem.

In the formulation, several dissolved chemical spe-

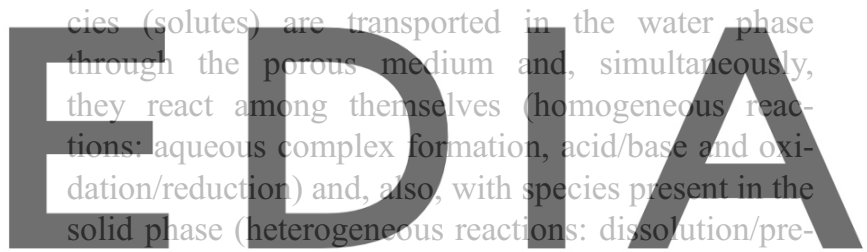

cipitation of minerals and cation exchange). The rele-

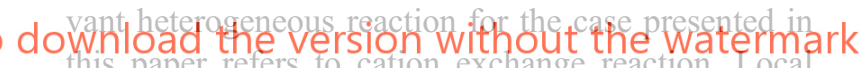
this paper refers to cation exchange reaction. Local equilibrium is assumed for all the chemical reactions and the solute transport mechanisms considered in the formulation are: advection (due to water phase movement), molecular diffusion and mechanical dispersion.

The development of the reactive transport equations uses the general approach by Lichtner (1985), Kirkner and Reeves (1988) and Steefel and Lasaga (1994). Starting from the mass balance equation of each one of the species present in the medium, the final independent transport equations are obtained using the restrictions arising from the various reversible chemical reactions (local equilibrium assumption).

Let us consider the reactive transport of $N$ chemical species in a deformable unsaturated porous medium. The transport of every one of those species can be expressed as:

$$
\frac{\partial}{\partial t}\left(\phi S_{\ell} \rho_{\ell} c_{i}\right)+\nabla \cdot\left(\lambda_{i} j_{i}\right)=R_{i} \quad(i=1, \ldots, N)
$$


where $\phi$ is the porosity, $S_{1}$ the liquid degree of saturation, $\rho_{1}$ the liquid density, $c_{i}$ the concentration of species $i$ in mol $/ \mathrm{kg}$ of solution and $R_{i}$ is the total production rate of species $i$ due to chemical reactions, in $\mathrm{mol} / \mathrm{m}^{3} / \mathrm{s}$. $\lambda_{i}$ is the mobility of species $i . \lambda_{i}$ is 1 if the species is in the liquid phase and 0 if it is in the solid phase. $j_{i}$ is the total flux of species $i$ expressed in $\mathrm{mol} / \mathrm{m}^{2} / \mathrm{s} . j_{i}$ is given by:

$j_{i}=\rho_{\ell} c_{i} q_{\ell}-\rho_{\ell} D_{\ell} \nabla c_{i}$

where $q_{\mathrm{w}}$ is the Darcy's flux and $D_{\mathrm{w}}$ the hydrodynamic dispersion tensor (molecular diffusion + mechanical dispersion).

It is now necessary to include the reactions in local equilibrium to obtain the set of independent concentrations in the system. If $N_{x}$ is the number of reversible independent reactions in a system containing $N$ species, the number of independent chemical components is $N_{\mathrm{c}}=N-N_{x}$. It is now possible to classify the system in $N_{\mathrm{c}}$ primary species and $N_{\mathrm{r}}$ secondary species.

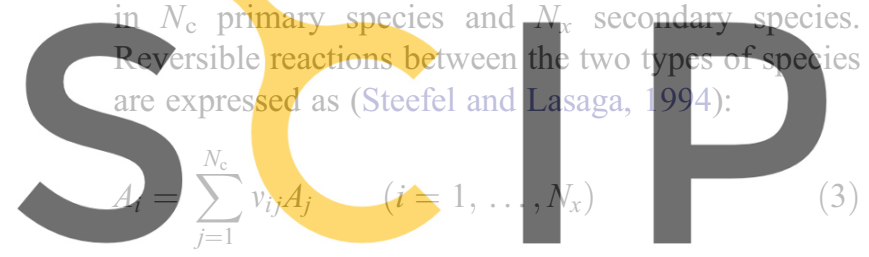

where $A_{j}$ and $A_{i}$ are the chemical formulas of the

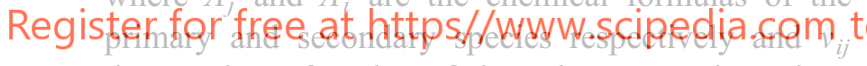

the number of moles of the primary species $j$ in a mole of the secondary species $i$. The general notation for the chemical reactions used in (3) allows the incorporation of the most relevant geochemical processes (e.g. hydrolysis, complex formation, acid/base reactions, oxidation/reduction reactions, dissolution/precipitation of minerals) into the formulation. Cation exchange reactions can also be written in accordance with (3). Appelo and Postma (1993) introduce this latter type of reaction in the chemical equilibrium problem without algorithm modifications.

Using the properties of the reversible reactions (3), it is possible to derive the basic transport equation:

$$
\begin{aligned}
& \frac{\partial}{\partial t}\left(\phi S_{\ell} \rho_{\ell} U_{j}\right)+\nabla \cdot\left(\rho_{\ell} U a_{j} q_{\ell}-D_{\ell} \nabla U a_{j}\right)=0 \\
& \quad\left(j=1, \ldots, N_{\mathrm{c}}\right) \\
& U_{j}=C_{j}+\sum_{i=1}^{N_{x}} v_{i j} X_{i} \quad\left(i=1, \ldots, N_{\mathrm{c}}\right)
\end{aligned}
$$

$$
U a_{j}=\lambda_{j} C_{j}+\sum_{i=1}^{N_{x}} v_{i j} \lambda_{i} X_{i} \quad\left(i=1, \ldots, N_{\mathrm{c}}\right)
$$

where $U_{j}$ is the total analytical concentration and $\mathrm{Ua}_{j}$ is the total aqueous concentration of the primary species $j . C_{j}$ and $X_{i}$ are the concentrations of the primary and secondary species, respectively, $\lambda_{j}$ and $\lambda_{i}$ are the mobilities of the primary and secondary species respectively.

In the present formulation, the total analytical concentrations $U_{j}$ are the unknowns of the transport Eq. (4), and $U a_{j}$ is considered a non-linear function of $U_{j}$. The link between the unknowns $U_{j}$ and the dependent variables $\mathrm{Ua}_{j}$ is the chemical equilibrium model that is based on the minimization of Gibbs Free Energy of the geochemical system represented by the reactions (3). To compute the concentrations of the species in equilibrium, a Newton-Raphson algorithm is applied

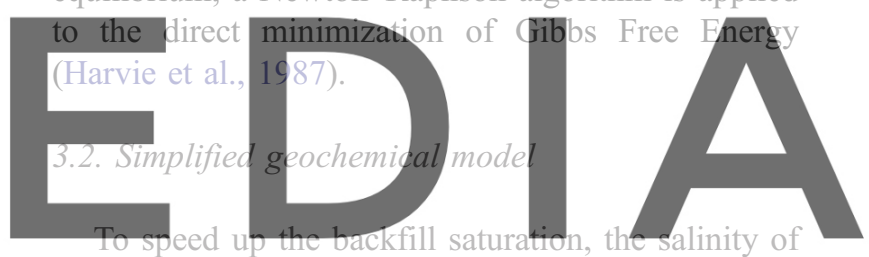

the Äspö water was increased adding $\mathrm{NaCl}$ and downtoadthe versionl twithout the (wotermark mass). Main chemical species present in the injected water, used to saturate the backfill, are shown in Table 1. The actual number of chemical species in the bentonite-fluid system is obviously bigger, as the processes involved in the bentonite-fluid system include reactions of dissolution-precipitation of carbonates, chalcedony and sulphates, dissolution of chlorides and its precipitation and ion exchange reactions, among others. Because of the limited geochemical information available on the backfill, the model was simplified and only the exchange reaction of $\mathrm{Na}^{+} / \mathrm{Ca}^{2+}$ was considered. These are, in fact, the most important exchangeable cations in the bentonite.

Table 1

Chemical analysis of the injected hydration water in the Backfill and Plug Test (Clay Technology, 1999)

\begin{tabular}{llll}
\hline $\mathrm{Cl}^{-}(\mathrm{mol} / \mathrm{L})$ & $\mathrm{Ca}^{2+}(\mathrm{mol} / \mathrm{L})$ & $\mathrm{Na}^{+}(\mathrm{mol} / \mathrm{L})$ & $\mathrm{pH}$ \\
\hline 0.2807 & 0.0720 & 0.1367 & 7.3 \\
\hline
\end{tabular}


Table 2

Scheme of the solved geochemical model during the simulation of backfill hydration

\begin{tabular}{ll}
\hline Primary aqueous species & $\mathrm{H}_{2} \mathrm{O}, \mathrm{Ca}^{2+}, \mathrm{Na}^{+}$and $\mathrm{Cl}^{-}$ \\
Species in the solid phase & $\mathrm{NaX}$ and $\mathrm{CaX}_{2}$ \\
Ion exchange reaction & $2 \mathrm{NaX}+\mathrm{Ca}^{2+}=\mathrm{CaX}_{2}+2 \mathrm{Na}^{+}$ \\
\hline
\end{tabular}

Table 2 shows the assumed backfill geochemical model.

\section{Backfill experimental study}

Several laboratory tests were carried out by Clay Technology during the development of the project in order to characterize the backfill. Additional laboratory experiments related to the material HC properties were performed by the authors as well. However, only the experimental work related to the analyses described in this paper are included here.

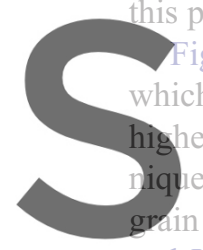
. 2 shows the backfill
was obtained combinin
for the smallest fractio
size is $20 \mathrm{~mm}$. Accordi

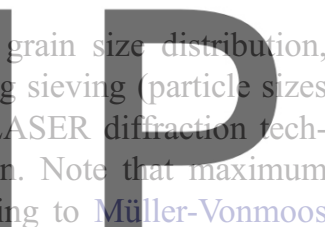

and Kahr (1983) and Madsen (1998), MX-80 bento-

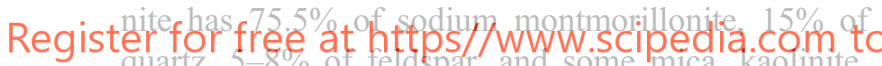
quartz, 5-8\% of feldspar, and some mica, Kaolinite, carbonate and pyrite. Regarding the size particles, $85 \%$ of its grains are smaller than $2 \mu \mathrm{m}$. Therefore fine particles of the mixture were provided mainly by the bentonite. MX-80 particle unit weight $\left(\gamma_{\mathrm{s}}\right)$ is 27.05 $\mathrm{kN} / \mathrm{m}^{3}$, its specific surface is $562 \mathrm{~m}^{2} / \mathrm{g}$ and the cation exchange capacity (CEC) is $76 \mathrm{meq} / 100 \mathrm{~g}(69.8 \mathrm{meq} /$ $100 \mathrm{~g}$ if only $\mathrm{Ca}^{2+}$ and $\mathrm{Na}^{+}$are taken into account as exchangeable cations). The cation exchange capacity of the mixture was calculated as the $30 \%$ of the bentonite CEC (20.94 meq/100 g considering only the $\mathrm{Ca}^{2+}$ and $\mathrm{Na}^{+}$as exchangeable cations).

Crushed granite particles came from the excavation of the gallery. Sweden is geologically located in the Fennoscandian shield or Baltic shield. This shield is dominated by gneisses and granitoids originated during the Precambrian age (Ericsson, 1999). The Småland granite intrusions dominate this Precambrian basement. At Äspö, this granite is called reddish grey Äspö diorite. It is one of the most basic and heavier varieties of the Småland granite (SKB, 1996).
Regarding the Backfill and Plug Experiment, granite rock was assumed chemically inert.

The initial MX-80 water content was $10.9 \%$ whereas crushed granite was assumed initially dry. Bentonite and crushed granite rock were mixed with salt water $\left(6 \mathrm{~g} / \mathrm{L} \mathrm{NaCl}+\mathrm{CaCl}_{2} 50 / 50\right.$ by mass $)$ and the final water content after the mixing process was around $12 \%$ and $13 \%$. The backfill particle unit weight is $26.4 \mathrm{kN} / \mathrm{m}^{3}$ calculated as a weighted average of their particle unit weights.

\subsection{Water uptake tests}

Clay Technology (1999) performed some water uptake tests with different salt concentrations to study salt effects on backfill hydraulic conductivity. Soil specimens $(10 \mathrm{~cm}$ height and $10 \mathrm{~cm}$ diameter) were dynamically compacted (5 layers) at initial water content between $10 \%$ and $13 \%$, using salt water of 6 $\mathrm{g} / \mathrm{L}$ of concentration. The initial dry specific weight
was $17.1 \mathrm{kN} / \mathrm{m}^{3}$ (void ratio 0.537 ). Backfil speci-
mens were connected to a water repository at atmo-
spheric pressure with different salt concentyations. As
hydration process started, the evolution of water con-
tent was measured at different tines extruding the soil sample and cutting it in five slices. Fig. 3 shows the downlution the version without the the watier wark water $(0.6 \%, 1.2 \%$ and $1.8 \%$, that is, 6,12 and 18 $\mathrm{g} / \mathrm{L}$ ). It is apparent that the higher the salt concentration, the faster the saturation process.

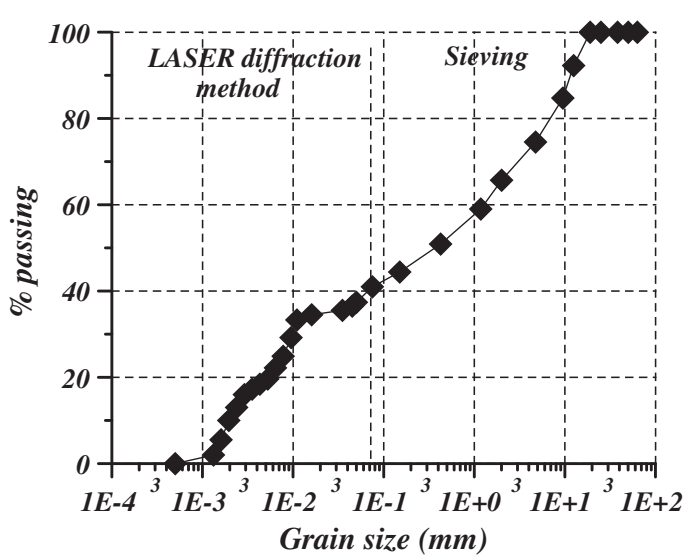

Fig. 2. Grain size distribution curve of the backfill used in the Backfill and Plug Test Project (Mata, 2003). 


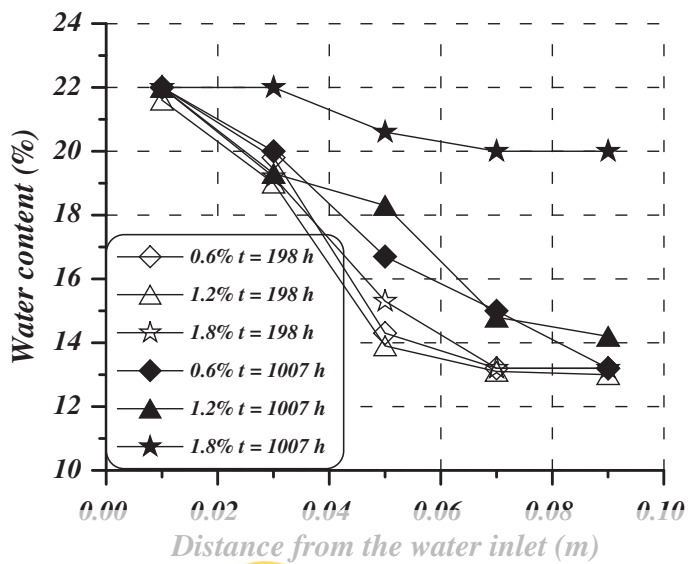

Fig. 3. Profiles of water content in water uptake tests for different salt concentrations and at different times - hours (Clay Technology, 1999)

4.2. Oedometer tests

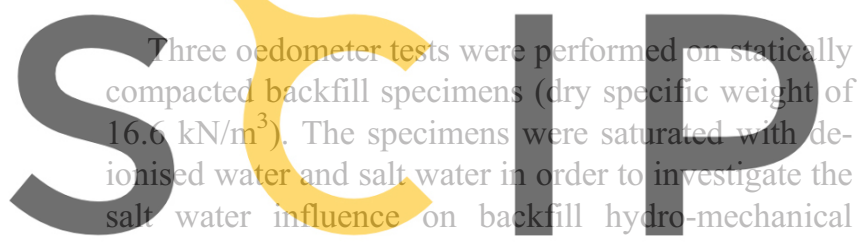

behaviour. Rowe cells of $152 \mathrm{~mm}$ of diameter were

Register for frese tests to account for the effegt of large particles. Initial water content of soil specimens ranged between $10 \%$ and $12 \%$, salt concentration in mixing water was $6 \mathrm{~g} / \mathrm{L}$, and soil specimens were compacted in one layer. Water containing three different salt concentrations was injected to saturate soil specimens $(0,6$ and $16 \mathrm{~g} / \mathrm{L})$. The proportion of $\mathrm{NaCl}$ and $\mathrm{CaCl}_{2}$ was $50 / 50$ by mass. The initial height of the sample was kept constant during the saturation process and the backfill swelling pressure was measured after saturation. Swelling pressure of the specimen saturated with de-ionised water was $196 \mathrm{kPa}$ and swelling pressure of the specimen saturated with salt water $(16 \mathrm{~g} / \mathrm{L})$ was $183 \mathrm{kPa}$ (Mata, 2003). Therefore, a small influence of the salt content on swelling pressure was indeed observed but the hydraulic behaviour was found to be more sensitive to that. This result is consistent with swelling and hydraulic tests performed in bentonite/sand mixtures by Dixon (2000) or in smectitic pure clay by Pusch (2001).

After full saturation of the specimens, the oedometer tests were carried out. Backfill compressibility was measured and backfill hydraulic conductivity was estimated as a function of saltwater content in the hydration water and the void ratio. Water collected from the saturation phase of the soil specimens was chemically analysed and the results are shown in Table 3 (only the considered chemical species in this geochemical model are indicated). Those analyses suggest the importance of the exchange process between $\mathrm{Na}^{+}$and $\mathrm{Ca}^{2+}$. Apparently, sodium bentonite is being transformed into calcium bentonite. In this context chemical processes are generally very slow and, therefore, maybe chemical equilibrium has not been achieved.

Three values of the intrinsic permeability were obtained at a void ratio of 0.54 from the interpretation of the oedometer tests performed using different salt waters for the backfill saturation. Due to the low content of bentonite of this mixture, the range of salt concentrations in this problem and the lack of

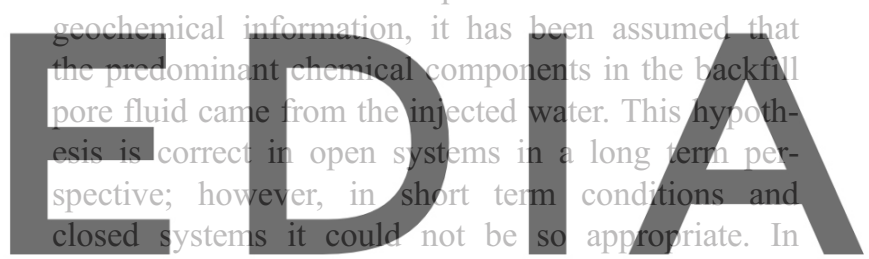

this work it is assumed that the barrier will behave

\section{down wo apd the version with tout the Baltic Sermark}

As this paper focuses on the coupling between hydraulic conductivity and salt content of permeant, it is reasonable to use total molar concentration of $\mathrm{NaCl}$ and $\mathrm{CaCl}_{2}$ as a control variable, because of the

Table 3

Results of the chemical analysis of collected water from soil specimen numbers 1,2 and 3

\begin{tabular}{lllll}
\hline Water & $\begin{array}{l}\mathrm{Na}^{+} \\
(\mathrm{mol} / \mathrm{L})\end{array}$ & $\begin{array}{l}\mathrm{Ca}^{2+} \\
(\mathrm{mol} / \mathrm{L})\end{array}$ & $\begin{array}{l}\mathrm{Cl}^{-} \\
(\mathrm{mol} / \mathrm{L})\end{array}$ & $\begin{array}{l}C \\
(\mathrm{~mol} / \mathrm{L})\end{array}$ \\
\hline 6 g/L mixing & 0.059 & 0.026 & 0.087 & 0.173 \\
$\begin{array}{l}\text { De-ionised water } \\
\text { injected }\end{array}$ & 0.000 & 0.000 & 0.000 & 0.000 \\
$\quad$ Sample number 1 & 0.258 & 0.011 & 0.097 & 0.367 \\
6 g/L injected & 0.051 & 0.027 & 0.105 & 0.183 \\
Sample number 2 & 0.255 & 0.012 & 0.167 & 0.435 \\
16 g/L injected & 0.136 & 0.072 & 0.280 & 0.489 \\
Sample number 3 & 0.309 & 0.023 & 0.299 & 0.632 \\
\hline
\end{tabular}

$C$ is the total molar concentration calculated as the sum of sodium, calcium and chloride concentrations. 
information available. Note, however, that there are many factors influencing that coupling, as for instance the valence of cations. This particular factor is difficult to consider in this case as sodium and calcium are mixed in the field test. In addition to that, other processes like gypsum or carbonate dissolution have been identified and they could influence permeability as well. Nowadays, further studies of the initial geochemical conditions in this backfill are being carried out to improve this hypothesis, but because of the multiple geochemical processes involved it is difficult to identify the contribution of each mechanism to permeability changes.

Fig. 4 shows the empirical law obtained from the interpretation of the oedometers, relating pore fluid chemistry and intrinsic permeability $k_{0}$. This relationship is of exponential type and depends on $\alpha$, a chemical parameter, $k_{0} *$, the initial intrinsic permeability and $C$, the molar concentration of salt in pore fluid (in mol/kg liquid phase

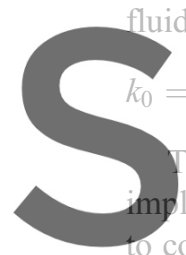
$k_{0}^{*} \exp (\alpha C)$

he mathematical fit of emented in the finite el
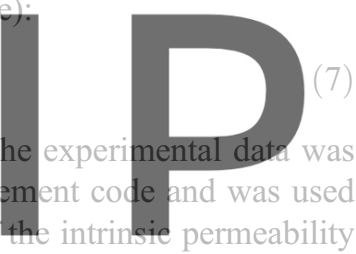

related to total salt concentration. The experimental Registesuforcfreenatl httaps//Niviw scipbe diadoomitto increased as the injected salt concentration increased. This is also consistent with experimental results from

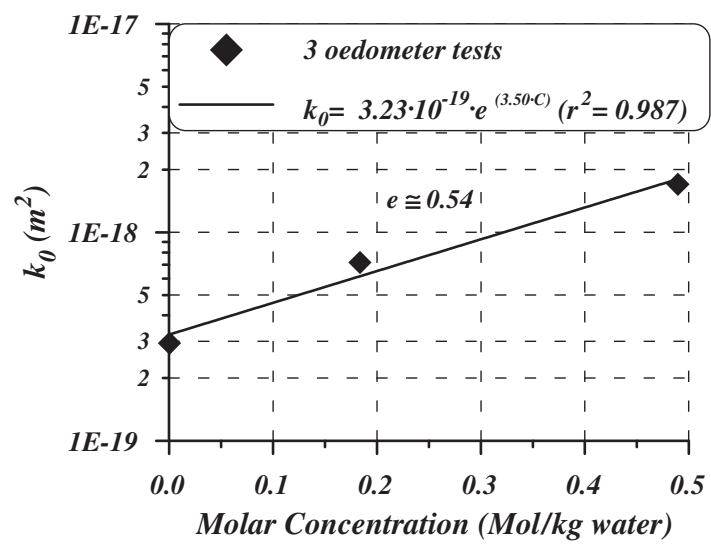

Fig. 4. Variation of intrinsic permeability with salt concentration in injected water in the three oedometer tests performed on compacted backfill samples (Mata, 2003). hydraulic tests on active clays where chemical influence of salts has been considered (i.e., Shackelford, 1994; Petrov and Rowe, 1997; Dixon, 2000; Pusch, 2001).

In general, the influence of pore fluid chemistry on hydraulic conductivity has been traditionally explained by means of the diffuse double layer theory (i.e., Mitchell, 1993). Thickness of the diffuse double layer decreases when increasing the concentration of electrolytes in the pore fluid or their valence, and that would explain backfill behaviour. Permeability is mainly controlled by the macropores, and, therefore, if the double layer is reduced clay aggregates will try to contract locally, leaving bigger pores in the structure. From a global perspective that change will not have important mechanical effects in this case. In fact bigger particles are inert and constitute $70 \%$ of the backfill material.

Although the hypotheses assumed by the double

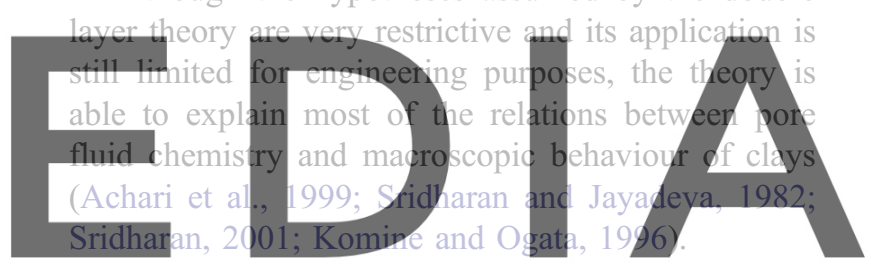

\section{dowinloadrtithe cuersion without the watermark}

Clay Technology (1997) studied the backfill retention curve of this mixture at the beginning of the project using the filter paper technique. In this way, backfill matric suction was measured. That curve is depicted in Fig. 5. Additionally, an experimental analysis of the osmotic suction on bentonite mixtures was also carried out by the authors, using sand instead of crushed rock in the mixture. It was assumed that this substitution of the big particles by sand should not have a significant influence on the osmotic suction. With this change, transistor psychrometers and vapour transfer technique were used and then the time required to perform the tests became reasonable. Sand mixed with pure bentonite was uniform poor-graded beach sand $\left(D_{10}=0.15 \mathrm{~mm}\right.$ and $\left.D_{60}=0.25 \mathrm{~mm}\right)$. Its air entry value varied from 2 to $5 \mathrm{kPa}\left(\gamma_{\mathrm{d}}=14.4 \mathrm{kN} / \mathrm{m}^{3}\right)$ and its particle unit weight was $26.0 \mathrm{kN} / \mathrm{m}^{3}$. Sand was washed with de-ionised water (electric conductivity $<3 \mu \mathrm{S} / \mathrm{cm}$ ) to take out salts and impurities that might be present, and then 


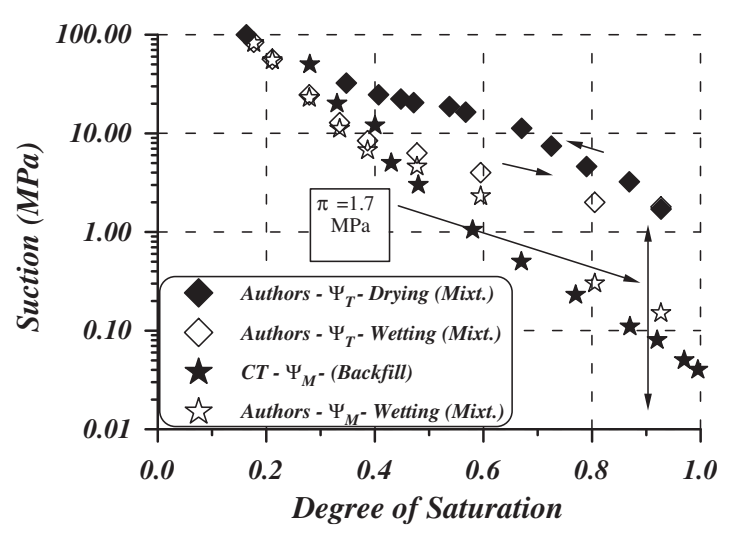

Fig. 5. Measured total suction $\left(\psi_{\mathrm{T}}=\psi_{\mathrm{M}}+\pi\right)$ of the bentonite-sand mixture in drying and wetting paths (Mata, 2003). From those curves osmotic suction $(\pi)$ was estimated as $1.7 \mathrm{MPa}$ approx. That value was assumed constant and subtracted from the wetting path to obtain the wetting mixture matric suction $\left(\psi_{\mathrm{M}}\right)$. The backfill matric suction, measured by Clay Technology (1997), is also shown
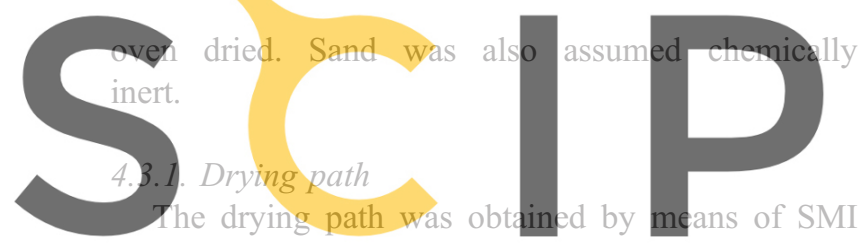

type transistor psychrometers (Woodburn et al., 1993)

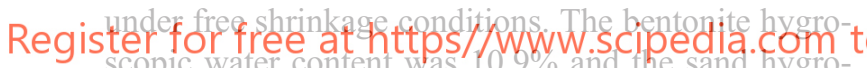

scopic water content was $0.1 \%$. Both were mixed at these initial water contents. $6 \mathrm{~g} / \mathrm{L}$ salt water was added in stages during the mixing process until water content of $12 \%$ was reached. When that value was achieved, $16 \mathrm{~g} / \mathrm{L}$ salt water was added until saturation (water content of $22.6 \%$ at $\gamma_{\mathrm{d}}=16.6 \mathrm{kN} / \mathrm{m}^{3}$ ). The mixture was then cured in a controlled humidity room for 48 $\mathrm{h}$, and it was statically compacted in a strain-controlled press. The height of the sample was $10 \mathrm{~mm}$ and the radius was $25 \mathrm{~mm}$. Two soil specimen tubes were inserted in this soil sample, extracting the final soil specimens. The rest of the soil sample was used to measure the water content after compaction. The final size of the specimens was $10 \mathrm{~mm}$ height and $15 \mathrm{~mm}$ of diameter.

The initial total suction was measured. This value would correspond to osmotic suction if matric suction is assumed to be zero at saturation state. Two points of the drying curve were obtained each day. Three hours were left with the soil specimen tubes open in a temperature controlled room $\left(22 \pm 1{ }^{\circ} \mathrm{C}\right.$, average relative humidity of $47 \%$ ) before measuring the suction and the water mass loss by evaporation, which means the ending of the first step of this multi-step path. At night, the soil specimen tubes were carefully sealed with plastic bags to prevent the evaporation of water in an uncontrolled manner. Fig. 5 shows the final curve obtained in this manner.

\subsubsection{Wetting path}

The wetting path was obtained from specimens prepared in the same way as in the drying path. Once the specimens were hydrated and compacted, they were kept in a room where the relative humidity was $47 \%$. When no more water losses were observed in the soil specimens, the residual water content was measured. The soil specimens were then introduced in sealed containers with different salt solutions. In this way, relative humidity was imposed within the small

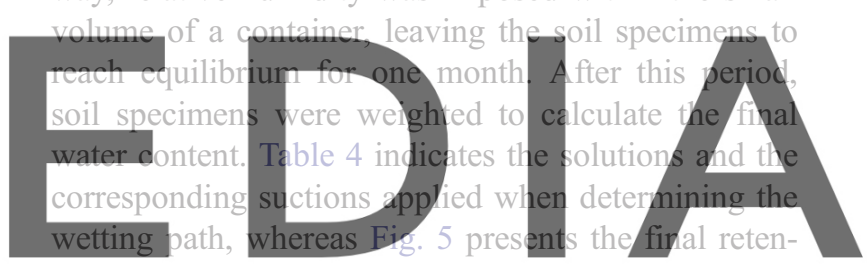

tion curve.

\section{o download the version without the watermark}

From the drying path performed on the sodium bentonite-sand mixture, the osmotic suction at the saturated state could be estimated as $1.7 \mathrm{MPa}$. There-

Table 4

Salts used by Mata (2003) to determine the main 30/70 bentonite/ sand wetting path

\begin{tabular}{ll}
\hline Salt solution & $\begin{array}{l}\text { Total suction } \\
\text { applied (MPa) }\end{array}$ \\
\hline $\mathrm{Mg}\left(\mathrm{NO}_{3}\right)_{2}$ (saturated) & $84.00^{\mathrm{a}}$ \\
$\mathrm{NaNO}_{2}$ (saturated) & $57.00^{\mathrm{a}}$ \\
$\left(\mathrm{NH}_{2}\right)_{2} \mathrm{SO}_{4}$ (saturated) & $24.50^{\mathrm{a}}$ \\
$\mathrm{CaSO}_{4}$ (saturated) & $12.80^{\mathrm{a}}$ \\
$\mathrm{KNO}_{3}$ (saturated) & $8.40^{\mathrm{a}}$ \\
$\mathrm{NaCl}\left(1.390 \mathrm{~mol} / \mathrm{kg} \mathrm{H} \mathrm{H}_{2} \mathrm{O}\right)$ & $6.30^{\mathrm{b}}$ \\
$\mathrm{NaCl}\left(0.896 \mathrm{~mol} / \mathrm{kg} \mathrm{H} \mathrm{H}_{2} \mathrm{O}\right)$ & $4.00^{\mathrm{b}}$ \\
$\mathrm{NaCl}\left(0.463 \mathrm{~mol} / \mathrm{kg} \mathrm{H} \mathrm{H}_{2} \mathrm{O}\right)$ & $2.00^{\mathrm{b}}$ \\
\hline
\end{tabular}

\footnotetext{
a Suction and concentration at saturation are available in Lide and Frederikse (1997).

b Suction and concentration are available in Romero (1999).
} 
fore, osmotic suction was defined as a constant value. This constant value was subtracted to the wetting retention curve measured after substituting the crushed granite by sand. In this way, the matric suction of the new mixture was estimated and compared with matric suction measured by Clay Technology on the original backfill. The three retention curves are depicted in Fig. 5. The results obtained by the authors (UPC) on the sand-bentonite mixture are consistent with those obtained by Clay Technology on the backfill material.

\section{Simulation of backfill saturation}

Some backfill constitutive parameters were obtained from the interpretation of the water uptake tests. Hydration of specimens with water containing $16 \mathrm{~g} / \mathrm{L}$ of salt concentration were numerically reproduced using CODE_BRIGHT, back-analysing the int insic permeability and permeability. The exponen

intrinsic permeability and

Salts present in the pore fluii
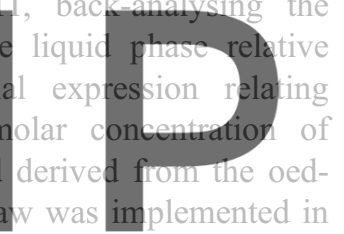

the $\mathrm{HC}$ formulation, in order to take into account the

Register fonceref reactive trangwort on hydraulic conduc-

the van Genuchten model using the matric retention

curve provided by Clay Technology (1997). The initial geochemical backfill conditions were assessed from data obtained in MX-80 pure bentonite at different saltwater concentrations and dry specific weights.

\subsection{Initial geochemical conditions}

The correct determination of the initial geochemical conditions of an active clay-fluid system is very important, although very difficult in general. The initial exchangeable cation contents and solutes in the bentonite are necessary to simulate such geochemical problems. The available experimental techniques to study these conditions are the squeezing technique and aqueous extracts tests, and such techniques are difficult to use in this backfill material. Initial backfill pore fluid chemical concentrations were obtained interpolating experimental data per- formed on pure compacted MX-80 specimens by Muurinen and Lehikoinen (1998a,b). They compacted several MX-80 specimens at different dry specific weights and put them in contact with different volumes of two external solutions, with different ionic strengths. After an interaction of about 300 days, the pore fluid of the specimens was squeezed out and analysed as well as the chemistry of the external solution. They defined the bentonite-water ratio $(B / W)$ as the total mass of bentonite divided by the volume of water connected to the sample, and they presented the experimental results as a function of that variable.

The bentonite-water ratio in the case of the ZEDEX gallery should be zero as backfill is connected to an open system (the Baltic Sea). However, if data with $B / W=0$ is considered, the concentrations in the open system remain constant. This might be the direction to which the process is going. However, in the repository, the surrounding system can be more
closed and timc dependent while full saturation and
chemical equilibrium are teached (Muurinen, 2002 .
In these conditions, the loyvest bentonite/ vater ratio
reported by Muturinen and Lehiko nen (998b) was
used to determine the initial gedchemical conditions $\left(B / W=15 \mathrm{~kg} / \mathrm{m}^{3}\right)$.

downjogad thews the evolution of contencentrion of pacted specimens were connected to two different salt

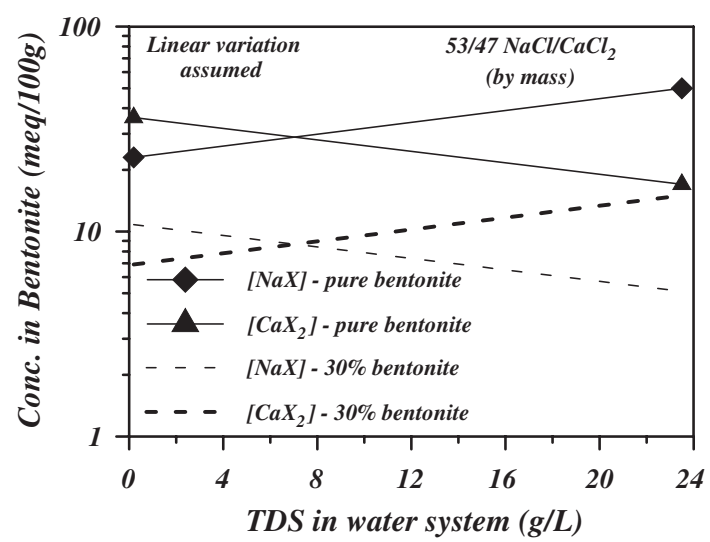

Fig. 6. Equilibrium concentrations of $\mathrm{NaX}$ and $\mathrm{CaX}_{2}$ in $\mathrm{MX}-80$ bentonite at two total dissolved salt concentrations (TDS) in the water connected to the soil samples at a bentonite/water ratio of 15 $\mathrm{kg} / \mathrm{m}^{3}$ (adopted from Muurinen and Lehikoinen, 1998b). 
solutions ( 0.19 and $23.5 \mathrm{~g} / \mathrm{L}$ of total dissolved salts) according to the experiments after Muurinen and Lehikoinen (1998b). A linear variation of $[\mathrm{NaX}]$ and $\left[\mathrm{CaX}_{2}\right]$ with the concentration of dissolved total salts in the connected solutions was assumed. The evolution of these two species were reduced to take into account the $30 \%$ of mass of bentonite in the backfill, and finally the values at $6 \mathrm{~g} / \mathrm{L}$ of salts were used as the initial $[\mathrm{NaX}]$ and $\left[\mathrm{CaX}_{2}\right]$. Table 5 shows the concentrations of the two exchangeable cations (10 and 9 meq/100 g respectively). Eq. (8) shows the mass action law of the exchange reaction written using the Gaines-Thomas convention:

$K_{\mathrm{Ca} / \mathrm{Na}}=\frac{a_{\mathrm{Na}^{+}} \cdot x_{\mathrm{Ca}}^{0.5}}{a_{\mathrm{Ca}^{2+}}^{0.5} \cdot x_{\mathrm{Na}}}$

where $x_{\mathrm{Na}}$ and $x_{\mathrm{Ca}}$ are the equivalent fractions of the exchangeable cations; $a_{\mathrm{Na}}^{+}$and ${a_{\mathrm{Ca}}^{2+}}^{2+}$ are the chemical activities of the cations in the solution, and $K_{\mathrm{Ca} / \mathrm{Na}}$ is the equilibrium constant of the ion exchange reaction (equal to 0.4 according to Appelo and Postma, 1993). The equivalent fraction of exchangeable cation is calculated by:

$$
\begin{aligned}
x_{i}= & \frac{\text { conc. of exchang. cation }(\mathrm{meq} / 100 \mathrm{~g} \text { of } \text { solid })}{C E C(\mathrm{meq} / 100 \mathrm{~g} \text { of solid })} \\
& \times \text { verifying } \sum_{i} x_{i}=1 \quad 0 \leq x_{i} \leq 1
\end{aligned}
$$

Chemical activities of the aqueous species were computed using the Harvie and Weare (1980) model, which belongs to the Pitzer family, valid for concentrated saline solutions. The concentration of chloride after the mixing process of the backfill with $6 \mathrm{~g} / \mathrm{L}$ of salt water was estimated taking into account the initial water content of the bentonite prior to the mixing. Finally, Table 5 also shows the initial concentrations of the primary species calculated using the exchangeable cations involved.

Table 5

Backfill geochemical initial conditions used in the computations

\begin{tabular}{llc}
\hline Exchangeable cations (meq/100 g) & $\mathrm{NaX}$ & 10.00 \\
& $\mathrm{CaX}_{2}$ & 9.00 \\
& $\mathrm{Na}^{+}$ & 0.0749 \\
Aqueous primary species & $\mathrm{Ca}^{2+}$ & 0.0020 \\
(mol/kg liquid phase) & $\mathrm{Cl}^{-}$ & 0.0789 \\
\hline
\end{tabular}

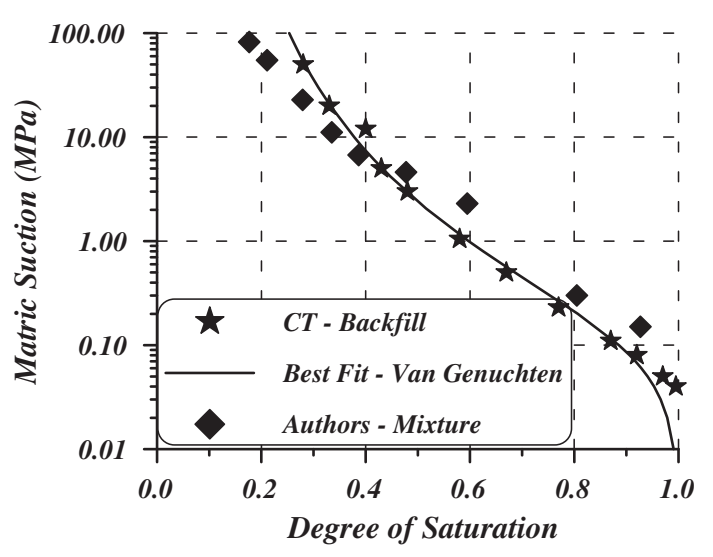

Fig. 7. Retention curve used in the calculations after obtaining the best fit of the matric suction relationship measured by Clay Technology (1997).

\subsection{Constitutive laws used in the calculations}

As the simulated problem is a saturation process, the wetting path was fit using the van Genuchten model:

$S_{\mathrm{e}}=\frac{S_{\ell}-S_{\mathrm{r} \ell}}{S_{\ell \mathrm{s}}-S_{\mathrm{r} \ell}}=\left(1+\left(\frac{p_{\mathrm{g}}-p_{\ell}}{p_{0}}\right)^{\frac{1}{1-\lambda}}\right)^{-\lambda}$

where $S_{\mathrm{e}}$ is the effective degree of saturation, $S_{\ell}$ is the degree of saturation of the liquid phase, $S_{\mathrm{r} \ell}$ is the residual degree of saturation, $S_{\ell \mathrm{s}}$ is the maximum degree of saturation, $p_{\mathrm{g}}$ is the gas pressure, $p_{\ell}$ is the liquid pressure, and $p_{0}$ and $\lambda$ are parameters of the model. Fig. 7 shows the best fit of the experimental data using this expression and the least squares approximation that corresponds to the parameters: $p_{0}=0.105 \mathrm{MPa}, \lambda=0.205, S_{\mathrm{r} \ell}=0.101$ and $S_{\ell \mathrm{s}}=1$.

In order to compute the flows of liquid and solute, the general theory for advection coupled with diffusion and dispersion as shown by Bear (1972) or by Auriault and Lewandowska (1996) has been considered. Generalized Darcy's law is used for the advective flux of the fluid mixture, whereas generalized Fick's law is employed for the diffusive and dispersive fluxes. Those expressions are assumed valid for this analysis, despite the changes in the solid phase due to chemical interactions with pore fluid. This is usually the case in the context of reactive transport in bentonite barriers (Bear, 1972; Guimarães, 2002). The couplings are therefore concentrated on the para- 


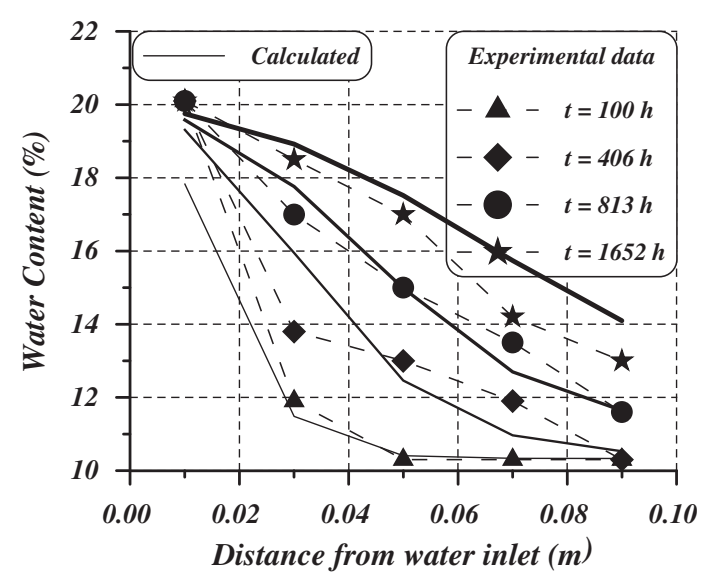

Fig. 8. Numerical simulation of the water uptake tests performed on the backfill hydrated with salt water $(16 \mathrm{~g} / \mathrm{L})$.

meters involved in the equations. Thus, intrinsic permeability was updated according to the changes in pore fluid chemistry, and it was introduced in the generalized Darcy's law. The advective flow of liquid phase was then computed as:

$$
\begin{aligned}
q_{\ell} & =-K_{\ell}\left(\nabla p_{\ell}-\rho_{\ell} \boldsymbol{g}\right)=-k_{0} \frac{k_{\mathrm{r} \ell} \gamma_{\ell}}{\mu_{\ell}} I\left(\nabla p_{\ell}-\rho_{\ell} \boldsymbol{g}\right) \\
& =-k_{0}^{*} e^{\left(\alpha\left(C-C_{0}\right)\right)} \frac{k_{\mathrm{r} \ell} \gamma_{\ell}}{\mu_{\ell}}\left(\nabla p_{\ell}-\rho_{\ell} \boldsymbol{g}\right)
\end{aligned}
$$

where $q_{1}$ is the advective flow of liquid phase, $K_{1}$ is the hydraulic conductivity tensor, $I$ is the identity

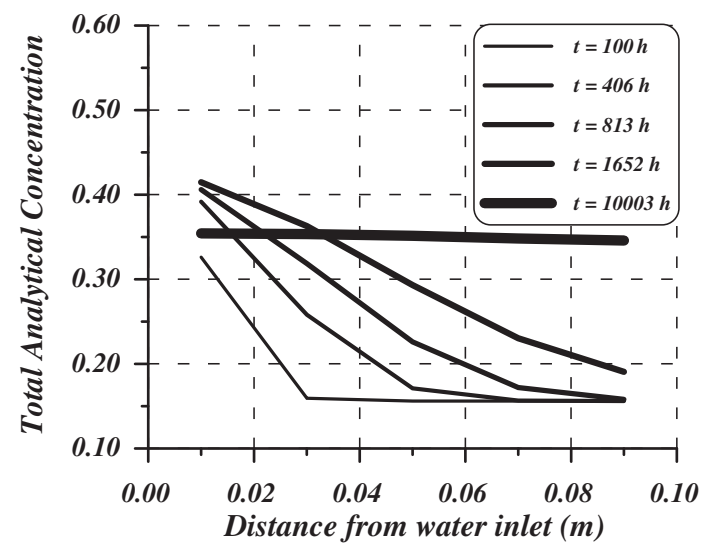

Fig. 9. Calculated evolution of the total analytical concentration during the saturation process in the water uptake test.

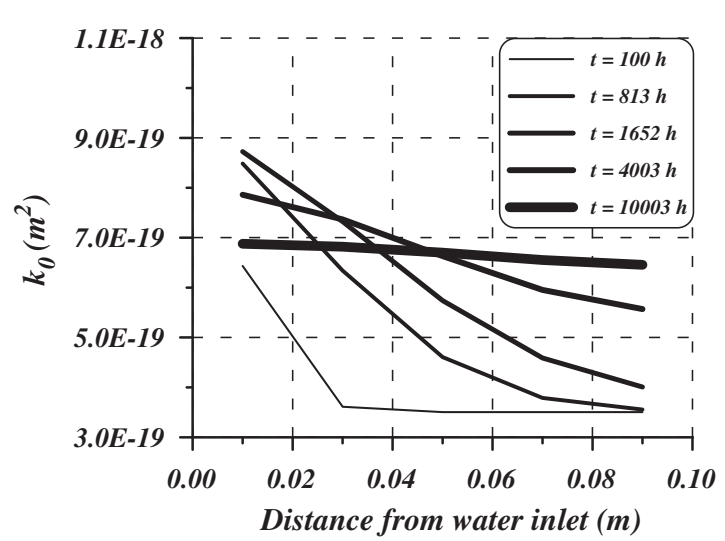

Fig. 10. Calculated evolution of the intrinsic permeability when backfill was hydrated with salt water $(16 \mathrm{~g} / \mathrm{L})$ in the water uptake test.

tensor, $p_{\ell}$ is the liquid pressure, $\boldsymbol{g}$ is the gravity vector, $k_{\mathrm{r} \ell}$ is the liquid phase relative permeability, $\mu_{\ell}$ is the liquid phase viscosity, $\gamma_{\ell}$ is the liquid phase specific weight, $\rho_{1}$ is the liquid phase density, $C$ is the total molar concentration of salt in the liquid phase, $k_{0}^{*}$ is the intrinsic permeability when $C=$ $C_{0}=\left[\mathrm{Na}^{+}\right]_{0}+\left[\mathrm{Ca}^{2+}\right]_{0}+\left[\mathrm{Cl}^{-}\right]_{0}$ from Table 5 , and $\alpha$ is the chemical parameter obtained from the exponential fit between the intrinsic permeability and the assumed pore fluid salt concentration.

The model used to calculate the liquid phase relative to permeability was proposed by Nielsen et al.

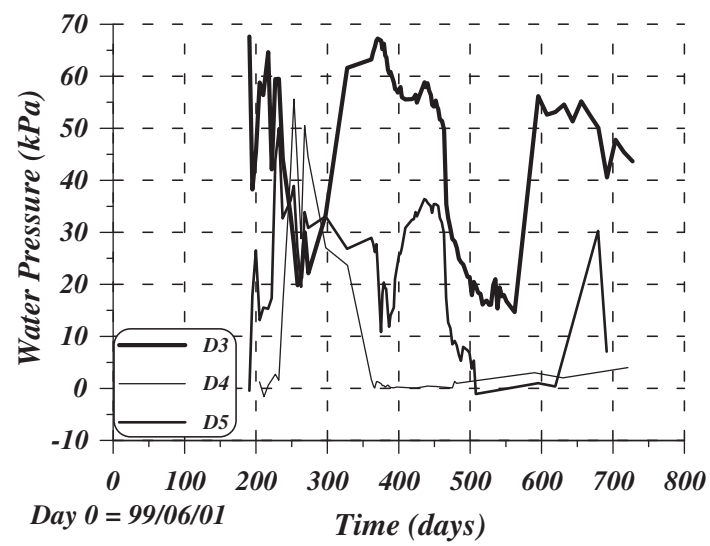

Fig. 11. Evolution of injected water pressure at mats D3, D4 and D5 (Goudarzi et al., 2002). The saturation process started 1st of June, 1999. 


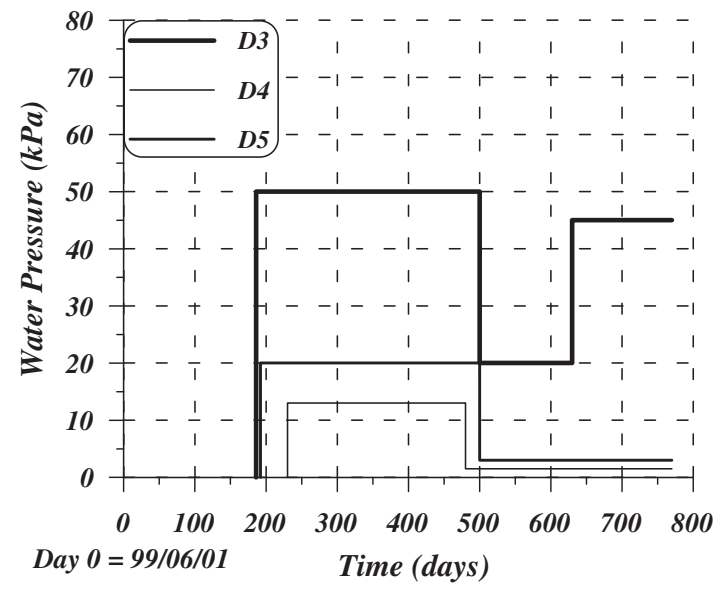

Fig. 12. Assumed evolution of the water pressure injected at mats D3, D4 and D5, which are surrounding sections A3 and A4. These simplified laws were chosen for simulation purposes in order to handle the real data coming from the in situ instrumentation.

(1986). It depends on the effective degree of saturation and on the experimental parameter $m$ :

$k_{\mathrm{r} \ell}=\sqrt{S_{\mathrm{e}}} \cdot\left\{1-\left(1-S_{\mathrm{e}}^{\frac{1}{m}}\right)^{m}\right\}^{2}$

Finally, the non-advective flow of solute $i$ was calculated by means of Fick's law, as:

$j_{i}=-D_{\ell} \nabla C_{i}=-\left(\phi \rho_{\ell} S_{\ell} \tau D_{\mathrm{m}} I+\rho_{\ell} D_{\ell}\right) \nabla C_{i}$

where $j_{i}$ is the non-advective flow of solutes in the liquid phase, $C_{i}$ is the concentration (in mol $/ \mathrm{kg}$ liquid phase) of specie $i, \tau$ is the soil tortuosity, $\phi$ is the soil porosity, $D_{\mathrm{m}}$ is the molecular diffusion and $D_{\ell}^{\prime}$ is the mechanical dispersivity tensor defined by expression (14) depending on $d_{1}$ and $d_{t}$, which are the longitudinal and transverse dispersivities of solutes in the liquid phase respectively:

$D_{\ell}^{\prime}=d_{\mathrm{t}}\left|q_{\ell}\right| I+\left(d_{\ell}-d_{\mathrm{t}}\right) \frac{q_{\ell} q_{\ell}^{\mathrm{t}}}{\left|q_{\ell}\right|}$

\subsection{Simulation of $1 D$ water uptake tests}

A series of water uptake tests hydrated with $16 \mathrm{~g} / \mathrm{L}$ salt water was simulated in order to backestimate the empirical coefficient of the liquid phase relative permeability ( $m$, Eq. (12)) and the initial intrinsic permeability $\left(k_{0}^{\prime}\right.$, Eq. (11)). Fig. 8 shows the comparison between measured computed water contents in the backfill samples, being hydrated with salt water of $16 \mathrm{~g} / \mathrm{L}$. The chemical parameter $\alpha$ was 3.5 , obtained from the oedometer tests (Fig. 4). The initial total concentration of salts in the liquid phase was 0.1556 $\mathrm{mol} / \mathrm{kg} \mathrm{H}_{2} \mathrm{O}$. Also, molecular diffusion was assumed to be $1 \cdot 10^{-10} \mathrm{~m}^{2} / \mathrm{s}$, corresponding to chloride apparent diffusion measured in MX-80 compacted specimens after Madsen (1998). Finally, soil tortuosity was taken as 1.0 and a value of $0.01 \mathrm{~m}$ was assumed for the longitudinal dispersivity $(10 \%$ of the total length of the 1D specimens).

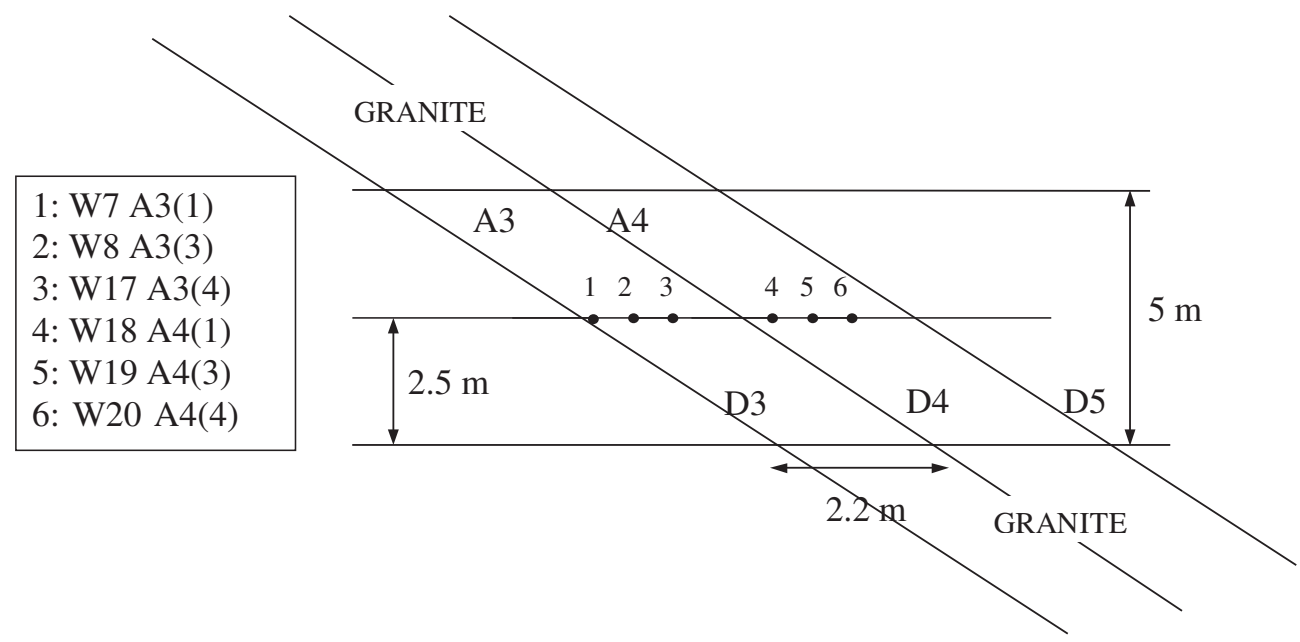

Fig. 13. Geometry considered for the 2D analyses of the saturation process and location of the six psychrometers used for comparison with field data. 


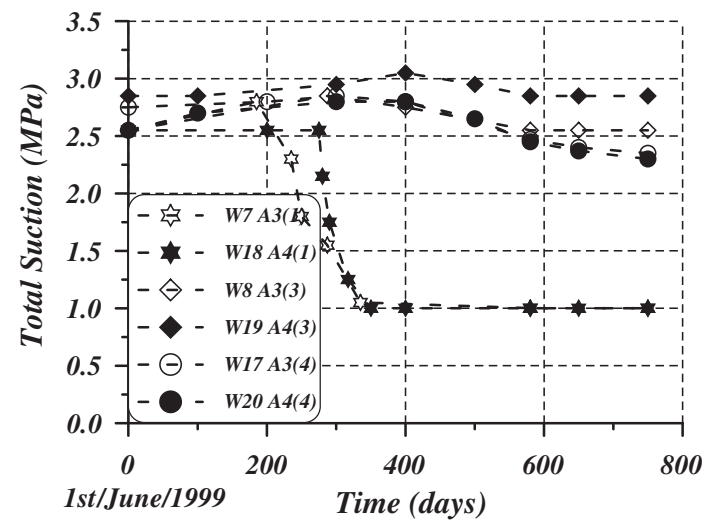

Fig. 14. Evolution of total suction measured in the 6 psychrometers placed in sections A3 and A4 at the ZEDEX gallery (Goudarzi et al., 2002).

The back-analysed initial intrinsic permeability was $3.5 \cdot 10^{-19} \mathrm{~m}^{2}$ and the potential coefficient of the liquid phase relative permeability resulted in $m=0.6$. The effect of the diffusion mechanism on the evolution of the hydraulic conductivity has proven to be important in this problem. The evolution of the intrinsic permeability is strongly dependent on the non-advective flow. In particular, the correct determination of backfill ion diffusion and dispersivities are important when reactive transport is considered. Fig. 9 shows the evolution of the computed total concentration and Fig. 10 shows the evolution of the intrinsic permeability. Intrinsic permeability reached a maximum close to the water inlet after $3000 \mathrm{~h}$, decreasing when solutes were transported due to the chemical gradient in the soil sample. Calculated time for full sample saturation was $6200 \mathrm{~h}$, however, chemical equilibrium was reached after $12000 \mathrm{~h}$.

After saturation and chemical equilibrium, the calculated value of intrinsic permeability was $6.7 \cdot 10^{-19}$ $\mathrm{m}^{2}$, which is slightly lower than the one obtained from the oedometer tests when backfill was hydrated and saturated with salt water containing $16 \mathrm{~g} / \mathrm{L}$ $\left(k_{0}=1.7 \cdot 10^{-18} \mathrm{~m}^{2}\right.$, Fig. 4), that is, the estimated hydraulic conductivity from the oedometer tests has been 2.5 times bigger than the estimated one fitting the results of the water uptake tests. Considering the information available, and the indirect procedures used for both estimations, the results seem to be reasonable. However, it should be pointed out that water uptake tests are performed far from saturation and, therefore, estimation of hydraulic conductivity from those measurements becomes more difficult.

\subsection{Simulation of the compacted backfill saturation at ZEDEX gallery}

A few Wescor PST-55 psychrometers are being used to monitor the total suction of compacted backfill in the ZEDEX gallery. In particular, some of them in sections A3 and A4 have been used for comparison with the simulations performed using the approach described. The mats surrounding these two sections are D3, D4 and D5. Injected water pressure in some permeable geotextiles since the beginning of the saturation process is shown in Fig. 11 (Goudarzi et al., 2002). Note that it was difficult in practice to keep

Table 6

Material properties used in the $2 \mathrm{D}$ simulation

\begin{tabular}{llllll}
\hline & & Granite & Disturbed granite & Mats & Backfill \\
\hline Ion exchange reaction $k_{\mathrm{Ca} / \mathrm{Na}}=0.4$ & $\mathrm{CEC}(\mathrm{meq} / 100 \mathrm{~g})$ & 0.0 & 0.0 & 0.0 & 20.94 \\
Advective flow & $k_{0}{ }^{*}\left(\mathrm{~m}^{2}\right)$ & $1 \cdot 10^{-17}$ & $1 \cdot 10^{-16}$ & $1 \cdot 10^{-10}$ & $3.5 \cdot 10^{-19}$ \\
& $B$ & 0.00 & 0.00 & 0.00 & 3.50 \\
Non-advective flow & $m$ & 3.00 & 3.00 & 2.00 & 1.00 \\
& $\tau$ & 1.00 & 1.00 & $2.5 \cdot 10^{-9}$ & 1.00 \\
& $D_{\mathrm{m}}\left(\mathrm{m}^{2} / \mathrm{s}\right)$ & $2.5 \cdot 10^{-9}$ & $2.5 \cdot 10^{-9}$ & 0.06 & $0.12^{-10}$ \\
Retention curve & $d_{1}=d_{\mathrm{t}}(\mathrm{m})$ & 0.12 & 0.12 & 0.05 & 0.105 \\
& $p_{0}(\mathrm{MPa})$ & 100 & 100 & 0.70 & 0.205 \\
& $\lambda$ & 0.195 & 0.195 & 0.10 & 0.101 \\
& $S_{\mathrm{rl}}$ & 0.10 & 0.10 & 1.00 & 1.00 \\
\hline
\end{tabular}

Backfill parameters were the same as in the simulation of the water uptake test (only the mechanical dispersivity was different). * Longitudinal dispersivity was chosen depending on the geometry $(0.12 \mathrm{~m}$ in the $2 \mathrm{D}$ geometry and $0.01 \mathrm{~m}$ in the $1 \mathrm{D}$ case). 


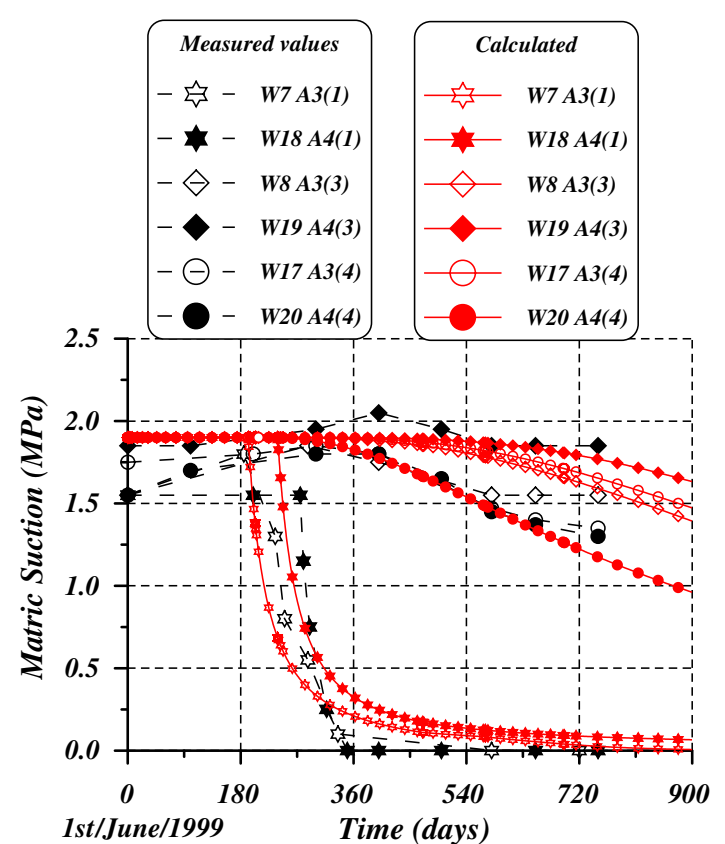

Fig. 15. Comparison between the computed matric suction using the hydro-chemical simulation and the measured values in the 6 psychrometers, using the parameters calibrated from the water uptake test.

constant values of injected water pressure. For the sake of simplicity, an easier profile was adopted for the numerical simulations, as presented in Fig. 12. Fig. 13 shows the geometry of the 2D problem considered in these calculations.

The evolution of total suction measured in these six psychrometers is depicted in Fig. 14. Some of the psychrometers indicated after saturation values of suc- tion around $1 \mathrm{MPa}$, and, therefore, this value was assumed as the osmotic suction. Thus, a constant value of 1.0 MPa was subtracted from the total suction measurements to compare the computed values and the measured ones. This value is slightly smaller than the one measured in the bentonite-sand mixture in the laboratory $(1.7 \mathrm{MPa})$, as indicated above. The reason for that difference may be the fact that bentonite-sand sample in the laboratory was probably not fully saturated when measuring the suction. In this case even a change of degree of saturation from $96 \%$ to $100 \%$ may lead to significant differences in suction, because of the logarithm dependence.

The assumed initial geochemical conditions in the two-dimensional simulation were the same as in the one-dimensional case (Table 5). Backfill parameters were also those obtained after the one-dimensional calibration of water uptake tests, although mechanical dispersivity was changed for the 2D simulation because of its dependence on the problem geometry. Four materials were considered in the 2D case: granite rock, disturbed granite rock, geotextile and backfill. Granite and geotextile were assumed chemically inert $(\mathrm{CEC}=0)$. Granite was always saturated and the parameters of the materials are summarised in Table 6.

Fig. 15 shows the comparison between the estimated matric suction, from the measured total suction at the six psychrometers, and the calculated matric suction by means of the finite element simulation taking into account the hydro-chemical coupling. Agreement between the calculated and measured values is good, considering the amount of variables involved in the problem. These results were obtained

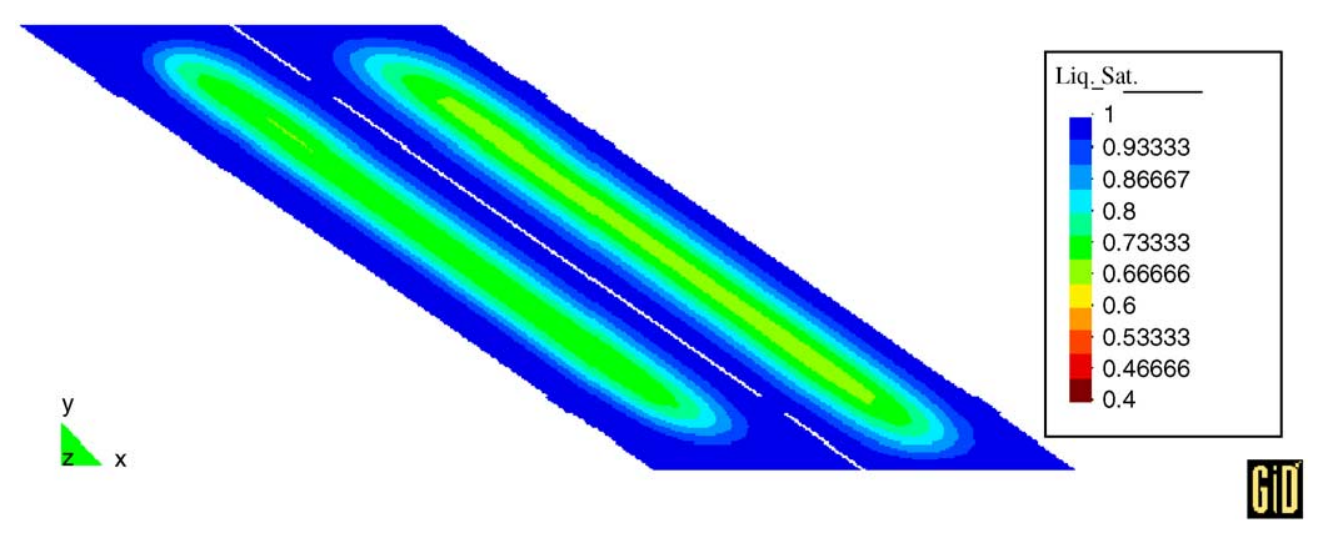

Fig. 16. Degree of saturation from analysis after 2200 days. 


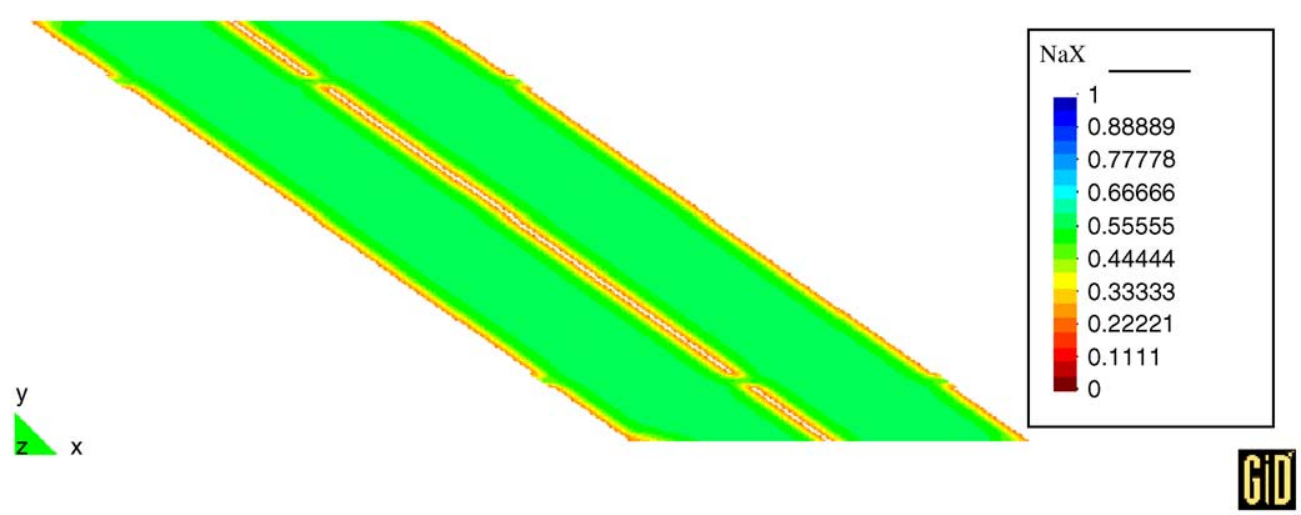

Fig. 17. Calculated equivalent fraction of $\mathrm{NaX}$ after 2200 days.

with the same parameters calibrated from the numerical analysis of the $16 \mathrm{~g} / \mathrm{L}$ water uptake tests.

Fig. 16 shows the backfill degree of saturation in sections A3 and A4 after 2200 days. According to the simulation, both sections are fully saturated after 9 years from the beginning of the process, assuming that injecting water pressure is constant. An increase of that water pressure would be necessary in order to reduce this time. Figs. 17 and 18 present the equivalent fraction of the exchangeable cation $\mathrm{NaX}$ and $\mathrm{CaX}_{2}$, respectively, after 2200 days. It is observed an increase of the adsorbed $\mathrm{Ca}^{2+}$ concentration and a reduction of $\mathrm{Na}^{+}$, both in the solid phase (bentonite losses sodium), that is, sodium bentonite is being transformed into calcium bentonite due to the exchange of sodium/ calcium, as suggested by the chemical analyses of the pore water from the oedometer tests. This transformation may change the behaviour of the bentonite if long term behaviour is studied. Finally, Fig. 19 shows the calculated intrinsic permeability after 2200 days. Though the backfill intrinsic permeability variation is not large, the simulation reflects the importance of the hydro-chemical coupling in the analysis of the backfill hydration process.

\section{Conclusions}

A coupled hydro-chemical (HC) approach was used to study the current saturation process of a MX-80 sodium bentonite and crushed granite rock mixture (30/ 70 by mass) compacted in situ at the ZEDEX gallery in the Äspö Hard Rock Laboratory in the Swedish Island of Äspö. The interest of this study was focused on the influence of salt concentration of hydrating water on the hydraulic behaviour of the mixture.

The authors carried out three oedometer tests with different salt concentration in the hydration water $(0,6$

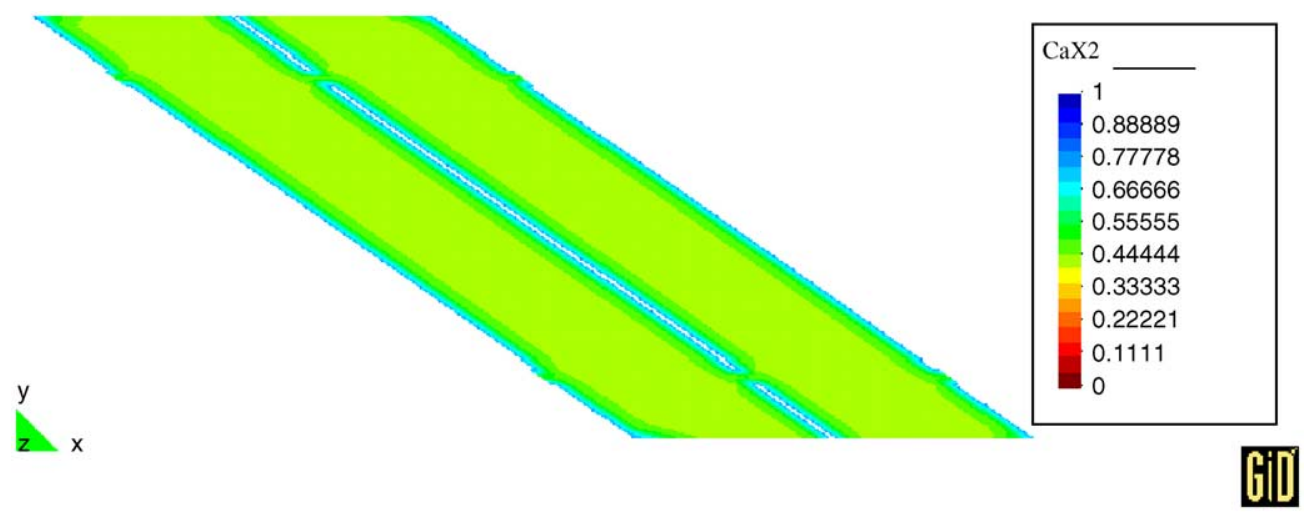

Fig. 18. Calculated equivalent fraction of $\mathrm{CaX}_{2}$ after 2200 days. 


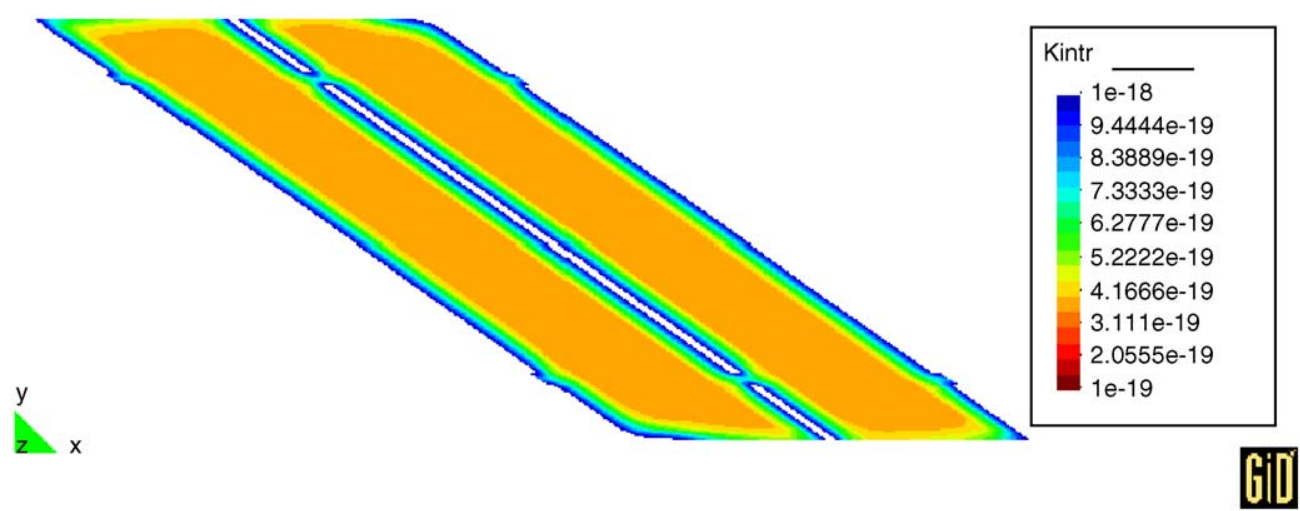

Fig. 19. Calculated intrinsic permeability $\left(\mathrm{m}^{2}\right)$ after 2200 days.

and $16 \mathrm{~g} / \mathrm{L})$ on statically compacted specimens (16.6 $\mathrm{kN} / \mathrm{m} 3$ ). From these tests an experimental law between the intrinsic permeability and the total concentration of salts in the liquid phase was determined. This experimental relationship was implemented in a finite element code to take into account the hydrochemical coupling observed in different laboratory test results. Moreover, the water retention properties of the backfill and of a MX-80 sodium bentonite-sand mixture ( $30 / 70$ by mass) were also studied taking into account the influence of the hydration with salt water. Osmotic suction was also determined from the drying retention curve of a bentonite-sand mixture mixed and hydrated with salt water.

Water uptake tests performed by Clay Technology were simulated and calibrated by means of this new formulation, obtaining the intrinsic permeability and the liquid phase relative permeability. The experimental and constitutive information was used to reproduce the evolution of the saturation process in the ZEDEX gallery. The evolution of six psychrometers installed in situ was successfully reproduced using this $\mathrm{HC}$ formulation.

The results showed that the hydro-chemical approach was able to explain the variation of the hydraulical behaviour when changes in pore fluid chemistry were considered. The sodium bentonite is transforming into a bentonite with higher calcium content in its solid phase. Under these conditions: dry specific weight $\left(16.6 \mathrm{kN} / \mathrm{m}^{3}\right)$, low content of bentonite of the mixture ( $30 \%$ by mass) and the low range of salt concentrations (up to $16 \mathrm{~g} / \mathrm{L}$ ), the hydraulic conductivity increased up to 6 times as salt concentration increased. Therefore, it becomes important to take into account chemical effects in the flow analysis in this type of problems. Full saturation of the backfill sections can be reached after 9 years if the water pressure is kept constant at the mats. Chemical equilibrium, however, requires more time. Thus, an increase of the injecting water pressure is necessary to reduce the predicted saturation time to a reasonable value. A step by step increment may be convenient in order to avoid hydraulic fracture.

A complete characterisation of the geochemical initial conditions and the evolution of chemical variables are required in order to improve the numerical simulations. Moreover, further analyses should consider a more complex geochemical model (i.e. additional species), although the experimental information available is still scarce because of the difficulties when studying the pore fluid chemistry of the bentonite/crushed granite system. In addition to that, it would be very interesting to extend in future analyses the HC coupling to the water retention curve, but this is difficult to carry out, both from the numerical and from the experimental point of view. In spite of that, the consistent results obtained in this case confirm the utility of this framework (even a simplified one) when studying coupled hydro-chemical hydration problems.

\section{Acknowledgements}

The support from ENRESA (Spanish nuclear waste Agency) through project "Backfill and Plug Test" (number 703268) is gratefully acknowledged. First 
author was also supported by a FI scholarship from Catalan Government, whereas second author was supported by a CAPES-Brasília/Brasil grant. Collaboration of SKB and Clay Technology concerning the field test is also gratefully acknowledged.

\section{References}

Achari, G., Joshi, R.C., Bentley, L.R., Chatterji, S., 1999. Prediction of the hydraulic conductivity of clays using the electric double layer theory. Can. Geotech. J. 36, 783-792.

Appelo, C.A.J., Postma, D., 1993. Geochemistry, Groundwater and Pollution. Balkema, Rotterdam, The Netherlands.

Auriault, J.L., Lewandowska, J., 1996. Diffusion/adsorption/advection macrotransport in soils. Eur. J. Mech. A, Solids 15 (4), 681-704.

Barbour, S.L., Fredlund, D.G., 1989. Mechanisms of osmotic flow and volume change in clay soils. Can. Geotech. J. 26, $551-562$.

Bear, J., 1972. Dynamics of Fluids in Porous Media. Dover Publications, Inc., New York.

Bolt, G., 1956. Physico-chemical analysis of the compressibility of pure clays. Géotechnique 6 (4), 695-707.

Börgesson, L., Johannesson, L.E., Sandén, T. 1996. Backfill materials based on crushed rock. Geotechnical properties determined in laboratory. SKB Progress Report HRL96-15. SKB, Stockholm, Sweden.

Cey, B.D., Barbour, S.L., Hendry, M.J., 2001. Osmotic flow through a cretaceous clay in southern Saskatchewan, Canada. Can. Geotech. J. 38, 1025-1033.

Clay Technology, 1997. Personal communication.

Clay Technology, 1999. Personal communication.

Di Maio, C., 1996. Exposure of bentonite to salt solution: osmotic and mechanical effects. Géotechnique 46 (4), 695-707.

Dixon, D.A., 2000. Pore Water Salinity and the Development of Swelling Pressure in Bentonite-Based Buffer and Backfill Materials. POSIVA Report OY 2000-04, ISBN 951-652-090-1, ISSN 1239-3096, Helsinki, Finland.

Dixon, D.A., Graham, J., Gray, M.N., 1999. Hydraulic conductivity of clays in confined tests under low hydraulic gradients. Can. Geotech. J. 36, 815-825.

Ericsson, L.O., 1999. Geoscientific R\&D for high-level radioactive waste disposal in Sweden. Current status and future plans. Eng. Geol. 52, 305-317.

Fernandez, F., Quigley, R.M., 1985. Hydraulic conductivity of natural clays permeated with simple liquid hydrocarbons. Can. Geotech. J. 22, 205-214.

Gens, A., Olivella, S., 2000. Non-isothermal multiphase flow in deformable porous media. Coupled formulation and application to nuclear waste disposal. In: Smith, A., Carter (Eds.), Developments in Theoretical Geomechanics. Balkema, Rotterdam, pp. 619-640.

Gens, A., García-Molina, A.J., Olivella, S., Alonso, E.E., Huertas, F., 1998. Analysis of a full scale in situ test simulating reposi- tory conditions. Int. J. Numer. Anal. Methods Geomech. 22, $515-548$.

Goldenberg, L.C., Magaritz, M., 1983. Experimental investigation on irreversible changes of hydraulic conductivity on the seawater-freshwater interface in coastal aquifers. Water Resour. Res. 19 (1), 77-85.

Goudarzi, R., Gunnarsson, D., Johannesson, L.-E. and Börgesson, L., 2002. Äspö Hard Rock Laboratory. Backfill and Plug Test. Sensors data report (period 990601-020101). Report $N^{\circ}$ 4. International Progress Report IPR-02-10. SKB, Stockholm, Sweden.

Greenberg, J.A., Mitchell, J.K., Witherspoon, P.A., 1973. Coupled salt and water flows in a groundwater basin. J. Geophys. Res. 78 (27), 6341-6353.

Guimarães, L., 2002. Análisis multi-componente no isotermo en medio poroso deformable no saturado. $\mathrm{PhD}$ thesis, Technical University of Catalonia, Barcelona, Spain (In Spanish).

Guimarães, L., Gens, A., Olivella, S., 1999. THM and reactive transport coupling in unsaturated porous media. Proc. 7th Int. Symp. on Numerical Models in Geomech., NUMOG VII. , pp. 303-308.

Guimarães, L., Gens, A., Sánchez, M., Olivella, S., 2001. A chemo-mechanical model for unsaturated expansive clays. In: Di Maio, C., Hueckel, T., Loret, B. (Eds.), International Workshop Clay Behaviour: Chemo-Mechanical Coupling, vol. 3. Maratea, Italy.

Guimarães, L., Gens, A., Olivella, S., 2002. Modelling the geochemical behaviour of an unsaturated clay subjected to heating and hydration. In: Jucá, J.F.T., de Campos, T.M.P., Marinho, F.A.M. (Eds.), Proc. 3rd Int. Conf. on Unsaturated Soils, UNSAT 2002, vol. 1. Balkema, Lisse, pp. 71-76 (Recife, Brazil).

Gunnarsson, D., Börgesson, L., Hökmark, H., Johannesson, L.E., Sandén, T., 2001. Äspö Hard Rock Laboratory. Report on the installation of the Backfill and Plug Test. International Progress Report IPR-01-07. SKB, Stockholm, Sweden.

Harvie, C., Weare, J., 1980. The prediction of mineral solubilities in natural water: the $\mathrm{Na}-\mathrm{K}-\mathrm{Ca}-\mathrm{Cl}-\mathrm{SO}_{4}-\mathrm{H}_{2} \mathrm{O}$ system to high concentration at $25{ }^{\circ} \mathrm{C}$. Geochim. Cosmochim. Acta 44, 981-997.

Harvie, C., Greenberg, J., Weare, J., 1987. A chemical equilibrium algorithm for highly non-ideal multiphase systems: free energy minimization. Geochim. Cosmochim. Acta 51, 1045-1057.

Hueckel, T., Tao, F., Cassiani, G., Pellegrino, A., 2001. Chemical softening and hardening of geomaterials in situ. In: Desai, T., et al., (Eds.), Computer Methods and Advances on Geomechanics, vol. 1. Balkema, Rotterdam, pp. 743-748.

Johannesson, L.E., Börgesson, L., Sandén, T., 1999. Backfill Materials Based on Crushed Rock (Part 2). Geotechnical Properties Determined in Laboratory. SKB ÄHRL, Stockholm, Sweden. (IPR-99-23).

Karnland, O., 1997. Bentonite Swelling Pressure in Strong $\mathrm{NaCl}$ Solutions. Correlation Between Model Calculations and Experimentally Determined Data. SKB, Stockholm, Sweden. (TR 97-31).

Keijzer, Th.J.S., Kleingeld, P.J., Loch, J.P.G., 1999. Chemical osmosis in compacted clayey material and the prediction of water transport. Eng. Geol. 53, 151-159.

Kemper, W.D., 1961. Movement of water as affected by free energy and pressure gradients: II experimental analysis of porous sys- 
tems in which free energy and pressure gradients act in opposite directions. Soil Sci. Soc. Am. J. 25, 260-265.

Kirkner, D., Reeves, H., 1988. Multicomponent mass transport with homogeneous and heterogeneous chemical reactions: effect of the chemistry on the choice of numerical algorithm. 1. Theory. Water Resour. Res. 24, 1719-1729.

Komine, H., Ogata, N., 1996. Prediction for swelling characteristics of compacted bentonite. Can. Geotech. J. 33, 11-22.

Latey, J., Kemper, W.D., Noonan, L., 1969. The effect of osmotic pressure gradients on water movements in unsaturated soils. Soil Sci. Soc. Am. J. 33, 15-18.

Lichtner, P., 1985. Continuum model for simultaneous chemical reactions and mass transport in hydrothermal systems. Geochim. Cosmochim. Acta 49, 779-800.

Lide, D.R., Frederikse, H.P.R., 1997. CRC Handbook of Chemistry and Physics. A Ready-Reference Book of Chemical and Physical Data. CRC Press, New York.

Madsen, F.T., 1998. Clay mineralogical investigations related to nuclear waste disposal. Clay Miner. 33, 109-129.

Marine, I.W., Fritz, S.J., 1981. Osmotic model to explain anomalous hydraulic heads. Water Resour. Res. 17, 73-82.

Mata, C., 2003. Analysis of the hydro-mechanical behaviour of a mixture of sodium bentonite and crushed granite rock used in the Backfill and Plug Test, Äspö (Sweden). PhD thesis, Dept. of Geotechnical Engineering, Technical University of Catalonia (UPC), Barcelona, Spain.

Mata, C., Romero, E., Ledesma, A., 2002. Hydro-chemical effects on water retention in bentonite-sand mixtures. In: Jucá, J.F.T., de Campos, T.M.P., Marinho, F.A.M. (Eds.), Proc. 3rd Int. Conf. on Unsaturated Soils, UNSAT 2002, vol. 1. Balkema, Lisse, pp. 283-288 (Recife, Brazil).

Mesri, G., Olsen, R., 1971. Consolidation characteristics of montmorillonite. Géotechnique 21 (4), 341-352.

Miller, D.J., Nelson, J.D., 1992. Osmotic suction as a valid state in unsaturated soils. Proc. 7th Int. Conf. Expansive Soils. Dallas Texas Tech University Press, Lubbock, USA, pp. 179-184.

Mitchell, J.K., 1993. Fundamentals of Soil Behavior, 2nd Edition. John Wiley and Sons, Inc., New York.

Mitchell, J.K., Greenberg, J.A., Whitherspoon, P.A., 1973. Chemico-osmotic effects in fine-grained soils. J. Soil Mech. Found. Div. 99 (SM4), 307-322.

Molenaar, M.M., Huyghe, J.M., 2001. An electro-chemo-mechanical mixture formulation of shale. In: Di Maio, C., Hueckel, T., Loret, B. (Eds.), International Workshop Clay Behaviour: Chemo-Mechanical Coupling, vol. 3. Maratea, Italy.

Müller-Vonmoos, M., Kahr, G., 1983. Mineralogische Untersuchungen von Wyoming Bentonit MX-80 und Montigel. NAGRA, Baden (NTB83-12 (In German)).

Murad, M., Cushman, J., 1998. A generalised biot's model for nonisothermal consolidation of clays incorporating physico-chemical effects. In: Thimus, M., et al., (Eds.), Poromechanics. Balkema, Rotterdam, pp. 111-116.

Muurinen, A., 2002. Personal communication.

Muurinen, A., Lehikoinen, J., 1998a. Evolution of the porewater chemistry in compacted bentonite. In: McKinley, I.G., McCombie, C. (Eds.), Scientific Basis for Nuclear Waste Management, XXI. Materials Research Society, Pennsylvania, pp. 415-422.
Muurinen, A., Lehikoinen, J., 1998b. Pore water chemistry in compacted bentonite. In: Pusch, R. (Ed.), Preprints of Contributions to the Workshop on Microstructural Modelling of Natural and Artificially Prepared Clay Soils with Special Emphasis on the Use of Clays for Waste Isolation Lund, Sweden, 12-14 October.

Neuzil, C.E., 2000. Osmotic generation of 'anomalous' fluid pressures in geological environments. Nature 403, 182-184.

Nielsen, D.R., Van Genuchten, M.Th., Biggar, J.W., 1986. Water flow and solute transport in the unsaturated zone. Water Resour. Res. 22 (9), 89S-108S.

Olivella, S., Gens, A., Carrera, J., Alonso, E.E., 1996. Numerical formulation for a simulator (CODE_BRIGHT) for the coupled analysis of saline media. Eng. Comput. 13, 87-112.

Petrov, R.J., Rowe, R.K., 1997. Geosynthetic clay liner (CGL) chemical compatibility by hydraulic conductivity testing and factors impacting its performance. Can. Geotech. J. 34, 863-885.

Pusch, R., 2001. Experimental study of the effect of high pore-water salinity on the physical properties of a natural smectitic clay. SKB, Technical Report, TR-01-07. SKB, Stockholm, Sweden.

Romero, E., 1999. Characterization and thermo-hydro-mechanical behavior of unsaturated Boom clay: an experimental study. $\mathrm{PhD}$ thesis, Dept. of Geotechnical Engineering, Technical University of Catalonia, Barcelona, Spain.

Shackelford, C.D., 1994. Waste-soil interaction that alter the hydraulic conductivity. In: Daniel, D.E., Trautwein, S.J. (Eds.), Proc. Hydraulic Conductivity and Waste Contaminant Transport in Soil. ASTM STP 1142. American Society for Testing and Materials, Philadelphia.

SKB (1996). Äspö Hard Rock Laboratory. 10 years of research. SKB, Hammarström, M. \& Olson, O. Eds.Stockholm, Sweden.

SKB (1999). Äspö Hard Rock Laboratory, Annual Report 1998. Publication TR-99-10. SKB, Stockholm, Sweden.

Sridharan, A., 2001. Engineering behaviour of clays: influence of mineralogy. In: Di Maio, C., Hueckel, T., Loret, B. (Eds.), International Workshop Clay Behaviour: Chemo-Mechanical Coupling. Maratea, Italy.

Sridharan, A., Jayadeva, M.S., 1982. Double layer theory and compressibility of clays. Géotechnique 32 (2), 133-144.

Steefel, C., Lasaga, A., 1994. A coupled model for transport of multiple chemical species and kinetic precipitation/dissolution reactions with application to reactive flow in single phase hydrothermal systems. Am. J. Sci. 294, 529-592.

Thomas, H.R., Cleall, P.J., Hashm, A.A., 2001. Thermal-hydraulicchemical-mechanical (THCM) behaviour of partly saturated soil. In: Desai, H.R., et al., (Eds.), Computer Methods and Advances on Geomechanics, vol. 1. . Balkema, Rotterdam, pp. 743-748.

Woodburn, J.A., Hold, J., Peter, P., 1993. The transistor psychrometer: a new instrument for measuring soil suction. In: Houston, S.L., Wray, W.K. (Eds.), Unsaturated Soils Geotechnical Special Publications No. 39, Dallas. ASCE, pp. 91-102.

Yanful, E.K., Shikatani, K.S., Quirt, D.H., 1995. Hydraulic conductivity of natural soils permeated with acid mine drainage. Can. Geotech. J. 32, 624-646.

Yeung, A.T., Mitchell, J.K., 1993. Coupled fluid, electrical and chemical flows in soil. Géotechnique 43, 121-134.

Young, A., Low, P.F., 1965. Osmosis in argillaceous rocks. Bull. Am. Assoc. Pet. Geol. 49, 1004-1008. 